\title{
Dose- and Time-Dependent Systemic Adverse Reactions of Sodium Carboxy Methyl Cellulose after Intraperitoneal Application in Rats
}

\author{
Chunguang Fan ( $\nabla$ fans19851029@aliyun.com ) \\ Shandong Quality Inspection Center for Medical Devices \\ Li Hou \\ shandong quality inspection center for medical devices \\ Guoxi Che \\ shandong quality inspection center for medical devices \\ Yanping Shi \\ shandong quality inspection center for medical devices

\section{Xiangdong Liu} \\ shandong quality inspection center for medical devices \\ Likui Sun \\ shandong quality inspection center for medical devices \\ Wensi Jia \\ shandong quality inspection center for medical devices \\ Fuyu Zhu \\ shandong quality inspection center for medical devices \\ Zenglin Zhao \\ shandong quality inspection center for medical devices \\ Ming Xu \\ shandong quality inspection center for medical devices \\ Xiaoxiao Gai \\ shandong quality inspection center for medical devices \\ Chenghu Liu \\ shandong quality inspection center for medical devices
}

\section{Research}

Keywords: sodium carboxy methyl cellulose, adverse effects, intraperitoneal application, systemic toxicity study, dose- and time-dependent effects, absorbable biomaterials

Posted Date: December 10th, 2020

DOl: https://doi.org/10.21203/rs.3.rs-122972/v1

License: (c) (1) This work is licensed under a Creative Commons Attribution 4.0 International License. Read Full License 


\section{Abstract}

Background: Sodium carboxy methyl cellulose (SCMC) is an important absorbable biomaterial for anti-adhesion and hemostasis medical devices used in the abdominal cavity. However, the systemic toxicity of SCMC following intraperitoneal route has not been revealed sufficiently.

Results: 3 SCMC solutions with gradient concentrations were intraperitoneally injected into 3 group rats respectively all at once to observe the dosedependence of systemic reactions of SCMC and 10 rats of each group were sacrificed $3 d, 7 d, 28 d$ and $90 \mathrm{~d}$ after injection to evaluate the time-dependence of the reactions. A range of adverse effects were shown in rats of high-dose $(2000 \mathrm{mg} / \mathrm{kg})$ group which were found varied with time extending and virtually disappeared 90 days after injection. Slight reactions were observed in medium-dose $(320 \mathrm{mg} / \mathrm{kg})$ group while negligible effects were found in lowdose $(50 \mathrm{mg} / \mathrm{kg})$ group.

Conclusion: The intraperitoneal application of SCMC can induce reversible systemic adverse effects to rats at the dose higher than $320 \mathrm{mg} / \mathrm{kg}$ and it is essential to take both dose- and time-dependent effects into account while designing a systemic toxicity study for absorbable biomaterials.

\section{Background}

As an absorbable macromolecular biomaterial, SCMC has been widely used for food additives and pharmaceutical excipients since it can form a gel when dissolved in water [1-3]. In the past decades, SCMC has been proven an effective material for anti-adhesion medical devices [4-11] because the viscosity of body fluids such as synovial fluid and aqueous humor can be mimicked by SCMC solutions which possess the ability to separate serosal and peritoneal surfaces during epithelial regeneration [10,11]. Furthermore, it is demonstrated that SCMC can be used as hemostasis materials due to its unique characteristics. Firstly, once it has contacted with blood, a gel can be formed which is able to block the ruptures in the capillaries. Meanwhile, the combination of acidic carboxy methyl of SCMC and $\mathrm{Fe}^{2+}$ in hemoglobin accelerates the adsorption of platelets and red blood cells. This allows the formation of thrombus. Additionally, the coagulation factors in the blood can be activated by SCMC, which enhances its hemostasis ability [12-15].

As a food additive and pharmaceutical excipient, SCMC is always ingested orally. Therefore, many studies have focused on its safety following oral route and it has been proved that no obvious adverse effects were detected $[2,3,16]$. Apart from its oral applications, the SCMC, as aforementioned, would be intraperitoneally administrated into the human body as anti-adhesion and hemostasis materials. According to ISO10993-1: 2018 [17], extractables/leachables can be introduced to the systemic circulation, lymphatic system, and/or cerebrospinal fluid and, therefore, systemic toxicity should be considered. For the evaluation of systemic toxicity, in IS010993-11: 2017 A.2 to A.10, several routes of administration are listed including implantation, inhalation, intraperitoneal, intravenous et al. Particularly, in IS010993-11, it is emphasized that the most clinically relevant route of administration shall be used [18]. Hence, it has significant importance to evaluate the systemic toxicity risks of SCMC following intraperitoneal route. However, up till now, no related research works has been reported.

According to IS010993-11, which is applicable to a broad range of medical devices, the systemic toxicity tests for absorbable biomaterials are designed to be limit tests accompany with single treatment duration [18]. However, such a study design has disadvantages. From the perspective of limit tests, which are uses of a single group treated at a suitable dosage of test sample in order to delineate the presence or absence of a toxic hazard, it is not able to obtain the detailed information of dose-response or dose-effect of SCMC. Furthermore, the treatment duration of the systemic toxicity test is generally fixed to, for example, 90 days for subchronic test in rodents following intraperitoneal route. Under this situation, the variation of toxic reactions over time cannot be investigated. Unlike systemic toxicity reactions of traditional non-absorbable materials, the reactions of absorbable biomaterials are closely related to its absorption, distribution, metabolism and excretion when applied to the body, which, in fact, may possess strong dose- and time-dependence. Therefore, proper study design has to be uniquely tailored to the nature of these absorbable materials and their intended clinical applications.

In this work, we designed a scientific and reasonable test to fully reveal the systemic toxicity of SCMC including its dose- and time-dependence following intraperitoneal route and, simultaneously, to provide an important reference for the clinical use of SCMC and for study design of absorbable biomaterials.

\section{Results}

Clinical observation and mortality

One day after intraperitoneal injection, one male rat in $28 \mathrm{~d}$ group of high-dose group was found dead. One male rat in $7 \mathrm{~d}$ group and another one in $28 \mathrm{~d}$ group of high-dose group died 2 days after injection. No toxic symptoms under clinical observation or mortality were observed in the rest animals during the study. Therefore, the mortality of rats of high-dose group was $7.5 \%$.

Body weight

The mean body weights (MBWs) of male rats in each group are presented in Table 1, from which it is clear that, for all time groups, high-dose SCMC slowed weight gain significantly in the first week just after injection. Over the subsequent weeks, despite the fact that the MBWs of high-dose group remained at a relatively low level, comparable growth rate to control group was observed, indicating the reduction of adverse effects over time. Meanwhile, medium and low dose of SCMC showed no significant effects on the MBW, as evidenced in Table 1. As a representative, the results of MBWs of $28 \mathrm{~d}$ group are shown in Fig. 1 for easy visualization and comparison. As for female rats, the MBWs of each test group were keeping the same with that of control group during the experimental procedure, showing rather weak dependence on dose and time. 
Table 1

Body weight data (mean $\pm S D$, male, $n=5$ )

\begin{tabular}{|c|c|c|c|c|c|}
\hline Time group & Week & C & $\mathrm{L}$ & $M$ & $\mathrm{H}$ \\
\hline \multirow[t]{2}{*}{$7 d$} & 0 & $223.4 \pm 6.6$ & $222.6 \pm 8.8$ & $224.0 \pm 4.6$ & $221.3 \pm 8.1$ \\
\hline & 1 & $281.6 \pm 13.8$ & $282.6 \pm 12.4$ & $279.2 \pm 9.1$ & $253.3 \pm 14.3^{\dagger \star \star} \downarrow$ \\
\hline \multirow[t]{5}{*}{$28 d$} & 0 & $214.8 \pm 4.9$ & $216.2 \pm 7.5$ & $217.0 \pm 6.0$ & $217.0 \pm 4.8$ \\
\hline & 1 & $270.0 \pm 8.2$ & $273.4 \pm 7.6$ & $279.0 \pm 6.0$ & $250.7 \pm 9.5^{\ddagger \star \star} \downarrow$ \\
\hline & 2 & $330.4 \pm 12.4$ & $330.8 \pm 16.2$ & $344.0 \pm 8.2$ & $314.0 \pm 16.4^{\ddagger \star \star} \downarrow$ \\
\hline & 3 & $369.0 \pm 10.9$ & $368.8 \pm 26.8$ & $382.2 \pm 10.7$ & $344.7 \pm 20.8^{\ddagger \star \star} \downarrow$ \\
\hline & 4 & $404.2 \pm 6.9$ & $399.4 \pm 33.7$ & $421.4 \pm 10.4$ & $387.3 \pm 21.1^{\ddagger \star \star \downarrow}$ \\
\hline \multirow[t]{5}{*}{$90 \mathrm{~d}$} & 0 & $215.6 \pm 5.6$ & $216.8 \pm 4.6$ & $215.4 \pm 5.1$ & $215.4 \pm 4.7$ \\
\hline & 1 & $269.6 \pm 8.4$ & $269.4 \pm 7.8$ & $268.4 \pm 6.5$ & $255.0 \pm 13.0 * \downarrow$ \\
\hline & 2 & $335.0 \pm 11.7$ & $327.4 \pm 21.8$ & $327.0 \pm 13.2$ & $314.6 \pm 19.3$ \\
\hline & 3 & $372.4 \pm 18.4$ & $363.8 \pm 33.7$ & $360.6 \pm 19.0$ & $350.8 \pm 29.9$ \\
\hline & 4 & $411.6 \pm 18.2$ & $404.6 \pm 31.4$ & $401.2 \pm 18.6$ & $390.4 \pm 29.0$ \\
\hline
\end{tabular}

${ }^{\dagger} n=4$ because 1 rat died 2 days after injection; ${ }^{\ddagger} n=3$ because 2 rats died in the initial 2 days after administration; **P ${ }^{*} 0.01$, compared to the control group; $\downarrow$ represents significant decrease. The data obtained between 5 to 13 weeks of $90 \mathrm{~d}$ group are not presented as no significant effects are observed.

Clinical pathology

As for male rats in 3d group injected with the high-dose of $2000 \mathrm{mg} / \mathrm{kg} \cdot \mathrm{BW}, 7$ hematology parameters of significant changes occurred, as shown in Table 2 , indicating strong effects of high-dose SCMC. Among these changes, the parameter of WBC was increased compared with control group, which was related to the SCMC-induced acute inflammatory response, while RBC, Hgb, Hct\% and PLT were decreased, suggesting hypersplenism occurred. Furthermore, adverse effect on coagulation function was considered to be responsible for the increase of PT and APTT. These results are further illustrated in Fig. 2 , in which the parameter variations of high-dose group can be clearly observed. 7 days after injection, the level of WBC of high-dose group was found to be comparable to that of the control group, while the variation amplitude of 6 other parameters decreased rapidly. 28 days after injection, slight changes occurred to parameters including RBC and APTT. These parameters, for rats in 90d group, were restored completely and thus are not listed in Table 2 . Meanwhile, for medium and low dose groups, negligible SCMC-induced effects on the hematology parameters were observed.

Table 2

Summary of hematology data (mean $\pm S D$, male, $n=5$ )

\begin{tabular}{|c|c|c|c|c|c|}
\hline $\begin{array}{l}\text { Time } \\
\text { group }\end{array}$ & Parameters & $\mathrm{C}$ & $\mathbf{L}$ & $M$ & $\mathrm{H}$ \\
\hline \multirow[t]{6}{*}{$3 d$} & WBC $\left(10^{9} / \mathrm{L}\right)$ & $4.50 \pm 1.02$ & $3.90 \pm 1.65$ & $4.61 \pm 0.74$ & $48.34 \pm 18.19 * * \uparrow$ \\
\hline & $\mathrm{RBC}\left(10^{12} / \mathrm{L}\right)$ & $6.32 \pm 0.41$ & $5.97 \pm 0.36$ & $5.75 \pm 0.25$ & $4.02 \pm 0.95^{\star \star} \downarrow$ \\
\hline & $\mathrm{Hgb}(\mathrm{g} / \mathrm{L})$ & $127.00 \pm 4.69$ & $123.20 \pm 4.44$ & $116.40 \pm 3.58$ & $82.20 \pm 18.94^{\star \star} \downarrow$ \\
\hline & $\operatorname{PLT}\left(10^{9} / \mathrm{L}\right)$ & $1114.40 \pm 33.90$ & $1034.40 \pm 87.59$ & $1026.60 \pm 67.81$ & $646.60 \pm 101.97^{* \star} \downarrow$ \\
\hline & PT (s) & $8.48 \pm 0.11$ & $8.56 \pm 0.58$ & $8.54 \pm 0.15$ & $8.96 \pm 0.31 * \uparrow$ \\
\hline & APTT (s) & $19.94 \pm 1.35$ & $19.76 \pm 1.04$ & $20.98 \pm 1.81$ & $31.18 \pm 4.74 * \star \uparrow$ \\
\hline $7 d$ & $\mathrm{Hgb}(\mathrm{g} / \mathrm{L})$ & $132.00 \pm 5.79$ & $128.60 \pm 5.03$ & $132.00 \pm 5.34$ & $118.25 \pm 6.08^{\dagger \star \star} \downarrow$ \\
\hline \multirow[t]{2}{*}{$28 \mathrm{~d}$} & $\mathrm{RBC}$ & $7.39 \pm 0.34$ & $7.50 \pm 0.19$ & $7.48 \pm 0.35$ & $6.94 \pm 0.14^{\star} \downarrow$ \\
\hline & APTT (s) & $18.12 \pm 0.73$ & $18.04 \pm 0.79$ & $18.02 \pm 0.90$ & $19.93 \pm 1.64^{\ddagger \star \uparrow}$ \\
\hline
\end{tabular}

Further investigations on the change of clinical chemistry parameters of male rats over dose and time were performed, the results of which are shown in Table 3. It is clear that intense parameter variations were induced by high-dose SCMC at the initial 3 days, while, with the time extending, these parameters 
gradually returned to their normal levels. Such a variation trend is coincident with that obtained from hematology parameters. It was found that, for $3 \mathrm{~d}$ group, the mean values of chemistry parameters including ALT, AST, ALP, Y-GT, TP, CHOL and TG were dramatically decreased, suggesting the high-dose SCMC induced liver function damage. The value of GLU was decreased, implying the adverse effects of glucose metabolism. Furthermore, electrolyte disturbance was induced by the high-dose SCMC which can be evidenced by the content change of ions such as $\mathrm{Ca}^{2+}, \mathrm{IP}_{\mathrm{N}} \mathrm{Na}^{+}$and $\mathrm{K}^{+}$.

For medium-dose group, partial of the changed parameters in high-dose group including TP in $3 \mathrm{~d}$ group as well as ALT, AST and CHOL in 7d group were also decreased compared to that of corresponding control group, indicating slight adverse effects caused by medium-dose of SCMC. It is worth noting, from Table 3, that significant statistical differences were observed between the medium- and high-dose groups for the parameters of TP (3d group), ALT (7d group) and AST (7d group), which further evidence the dose effects of injected SCMC. For easy comparison, the values of these parameters obtained from four groups are illustrated in Fig. 3. Furthermore, low-dose SCMC induced negligible clinical chemistry parameter variations.

Tables 4 and 5 show the corresponding parameters of female rats, which demonstrate similar variation trends to that of male ones. 
Table 3

Summary of clinical chemistry data (mean $\pm S D$, male, $n=5$ )

\begin{tabular}{|c|c|c|c|c|c|}
\hline $\begin{array}{l}\text { Time } \\
\text { group }\end{array}$ & Parameters & C & L & M & $\mathrm{H}$ \\
\hline \multirow[t]{13}{*}{$3 d$} & $\operatorname{ALT}(\mathrm{U} / \mathrm{L})$ & $34.76 \pm 4.84$ & $33.04 \pm 5.87$ & $35.18 \pm 8.00$ & $21.04 \pm 4.09 * \star \downarrow$ \\
\hline & AST (U/L) & $123.30 \pm 19.83$ & $132.12 \pm 25.28$ & $104.36 \pm 8.85$ & $72.42 \pm 15.46^{\star \star} \downarrow$ \\
\hline & ALP (U/L) & $363.64 \pm 24.48$ & $373.46 \pm 75.11$ & $336.24 \pm 55.39$ & $223.44 \pm 96.94^{\star \star} \downarrow$ \\
\hline & Y-GT (U/L) & $0.78 \pm 0.26$ & $0.65 \pm 0.21$ & $0.58 \pm 0.12$ & $0.43 \pm 0.14^{\star \star} \downarrow$ \\
\hline & $\mathrm{TP}(\mathrm{g} / \mathrm{L})$ & $46.92 \pm 1.66$ & $46.46 \pm 0.91$ & $44.62 \pm 0.87 \star \downarrow$ & $33.98 \pm 1.57^{\star \star} \downarrow^{\# \# \downarrow}$ \\
\hline & $\operatorname{ALB}(g / L)$ & $33.34 \pm 1.04$ & $34.10 \pm 0.76$ & $32.92 \pm 0.85$ & $32.50 \pm 1.40$ \\
\hline & GLU (mmol/L) & $5.45 \pm 0.25$ & $5.57 \pm 0.48$ & $5.62 \pm 0.60$ & $6.08 \pm 0.41 * \uparrow$ \\
\hline & $\mathrm{CHOL}(\mathrm{mmol} / \mathrm{L})$ & $1.69 \pm 0.12$ & $1.93 \pm 0.30$ & $1.71 \pm 0.23$ & $1.03 \pm 0.30^{\star \star} \downarrow$ \\
\hline & $\mathrm{TG}(\mathrm{mmol} / \mathrm{L})$ & $0.27 \pm 0.07$ & $0.35 \pm 0.11$ & $0.32 \pm 0.13$ & $0.14 \pm 0.09 * \downarrow$ \\
\hline & $\mathrm{Ca}^{2+}(\mathrm{mmol} / \mathrm{L})$ & $2.29 \pm 0.06$ & $2.27 \pm 0.03$ & $2.35 \pm 0.06$ & $2.71 \pm 0.08^{\star \star} \uparrow$ \\
\hline & $\mathrm{IP}(\mathrm{mmol} / \mathrm{L})$ & $2.97 \pm 0.07$ & $2.87 \pm 0.21$ & $2.83 \pm 0.16$ & $2.48 \pm 0.24^{\star \star} \downarrow$ \\
\hline & $\mathrm{Na}^{+}(\mathrm{mmol} / \mathrm{L})$ & $144.20 \pm 0.53$ & $144.12 \pm 0.51$ & $144.18 \pm 0.86$ & $148.88 \pm 2.62^{\star \star} \uparrow$ \\
\hline & $\mathrm{K}^{+}(\mathrm{mmol} / \mathrm{L})$ & $4.20 \pm 0.08$ & $4.17 \pm 0.14$ & $4.16 \pm 0.15$ & $3.90 \pm 0.21^{\star \star} \downarrow$ \\
\hline \multirow[t]{11}{*}{$7 d$} & ALT (U/L) & $36.90 \pm 3.77$ & $38.14 \pm 2.89$ & $27.70 \pm 2.12^{\star \star} \downarrow$ & $20.35 \pm 1.22^{\dagger \star \star} \downarrow^{\# \#} \downarrow$ \\
\hline & AST (U/L) & $142.60 \pm 16.71$ & $130.82 \pm 22.41$ & $115.52 \pm 20.70 \star \downarrow$ & $69.65 \pm 5.71^{\dagger \star \star} \downarrow^{\#} \downarrow$ \\
\hline & $\mathrm{TP}(\mathrm{g} / \mathrm{L})$ & $48.52 \pm 0.88$ & $45.58 \pm 0.55$ & $46.88 \pm 2.66$ & $40.20 \pm 2.10^{\dagger \star \star} \downarrow$ \\
\hline & $\operatorname{ALB}(\mathrm{g} / \mathrm{L})$ & $34.60 \pm 0.69$ & $33.00 \pm 0.95$ & $34.40 \pm 1.31$ & $32.53 \pm 2.33^{\dagger \star \downarrow}$ \\
\hline & GLU (mmol/L) & $5.89 \pm 0.42$ & $5.87 \pm 0.26$ & $6.24 \pm 0.36$ & $6.50 \pm 0.32^{\dagger \star \star \uparrow}$ \\
\hline & CHOL (mmol/L) & $2.06 \pm 0.51$ & $1.51 \pm 0.41 * \downarrow$ & $1.55 \pm 0.28^{\star} \downarrow$ & $1.16 \pm 0.21^{\dagger \star \star} \downarrow$ \\
\hline & TG (mmol/L) & $0.25 \pm 0.16$ & $0.18 \pm 0.07$ & $0.17 \pm 0.05$ & $0.10 \pm 0.03^{\dagger \star \downarrow}$ \\
\hline & $\mathrm{Ca}^{2+}(\mathrm{mmol} / \mathrm{L})$ & $2.33 \pm 0.06$ & $2.28 \pm 0.04$ & $2.30 \pm 0.04$ & $2.45 \pm 0.03^{\dagger \star \star \uparrow}$ \\
\hline & IP (mmol/L) & $2.95 \pm 0.14$ & $2.89 \pm 0.09$ & $2.90 \pm 0.08$ & $2.68 \pm 0.10^{\dagger \star \star} \downarrow$ \\
\hline & $\mathrm{Na}^{+}(\mathrm{mmol} / \mathrm{L})$ & $144.54 \pm 2.07$ & $145.70 \pm 0.60$ & $145.34 \pm 1.31$ & $146.43 \pm 1.38^{\dagger \star \uparrow}$ \\
\hline & $\mathrm{K}^{+}(\mathrm{mmol} / \mathrm{L})$ & $4.21 \pm 0.15$ & $4.06 \pm 0.31$ & $4.22 \pm 0.41$ & $3.89 \pm 0.24$ \\
\hline \multirow[t]{3}{*}{$28 d$} & $\operatorname{ALP}(U / L)$ & $236.66 \pm 44.18$ & $227.98 \pm 93.18$ & $214.22 \pm 44.08$ & $150.20 \pm 33.00^{\ddagger}$ \\
\hline & $\mathrm{Na}^{+}(\mathrm{mmol} / \mathrm{L})$ & $145.90 \pm 1.22$ & $146.28 \pm 0.69$ & $145.18 \pm 1.47$ & $147.93 \pm 0.90^{\ddagger \star \uparrow}$ \\
\hline & $\mathrm{K}^{+}(\mathrm{mmol} / \mathrm{L})$ & $4.33 \pm 0.14$ & $4.46 \pm 0.28$ & $4.38 \pm 0.15$ & $3.91 \pm 0.23^{\ddagger \star} \downarrow$ \\
\hline $90 d$ & $\operatorname{ALP}(U / L)$ & $120.16 \pm 17.71$ & $129.82 \pm 30.42$ & $141.48 \pm 34.11$ & $133.78 \pm 18.18$ \\
\hline
\end{tabular}


Table 4

Summary of hematology data (mean $\pm S D$, female, $n=5$ )

\begin{tabular}{|c|c|c|c|c|c|}
\hline $\begin{array}{l}\text { Time } \\
\text { group }\end{array}$ & Parameters & C & $\mathbf{L}$ & $M$ & $\mathrm{H}$ \\
\hline \multirow[t]{7}{*}{$3 d$} & WBC $\left(10^{9} / \mathrm{L}\right)$ & $3.33 \pm 0.77$ & $3.31 \pm 0.52$ & $2.96 \pm 1.00$ & $28.04 \pm 16.45^{\star \star} \uparrow$ \\
\hline & $\operatorname{RBC}\left(10^{12} / \mathrm{L}\right)$ & $6.08 \pm 0.23$ & $6.21 \pm 0.20$ & $5.75 \pm 0.43$ & $4.71 \pm 0.70^{\star \star} \downarrow$ \\
\hline & $\mathrm{Hgb}(\mathrm{g} / \mathrm{L})$ & $127.20 \pm 5.45$ & $123.20 \pm 4.02$ & $120.20 \pm 7.33$ & $97.60 \pm 16.50^{\star \star} \downarrow$ \\
\hline & Hct (\%) & $36.40 \pm 1.25$ & $35.16 \pm 1.09$ & $34.32 \pm 1.89$ & $29.24 \pm 4.03^{\star \star} \downarrow$ \\
\hline & PLT $\left(10^{9} / \mathrm{L}\right)$ & $1156.20 \pm 68.58$ & $1114.80 \pm 49.72$ & $1070.40 \pm 90.41$ & $814.00 \pm 188.18^{* \star} \downarrow$ \\
\hline & PT (s) & $7.78 \pm 0.19$ & $7.82 \pm 0.26$ & $7.74 \pm 0.05$ & $7.98 \pm 0.22$ \\
\hline & APTT (s) & $16.46 \pm 0.54$ & $16.74 \pm 1.30$ & $18.20 \pm 0.82$ & $26.58 \pm 6.18^{\star \star} \uparrow$ \\
\hline \multirow[t]{6}{*}{$7 d$} & $\operatorname{RBC}\left(10^{12} / \mathrm{L}\right)$ & $6.06 \pm 0.58$ & $6.28 \pm 0.22$ & $6.21 \pm 0.38$ & $6.07 \pm 0.60$ \\
\hline & $\mathrm{Hgb}(\mathrm{g} / \mathrm{L})$ & $125.40 \pm 12.90$ & $128.80 \pm 1.30$ & $125.00 \pm 6.96$ & $121.20 \pm 10.01$ \\
\hline & Hct (\%) & $35.08 \pm 3.24$ & $36.08 \pm 0.69$ & $35.18 \pm 2.02$ & $34.68 \pm 2.79$ \\
\hline & PLT $\left(10^{9} / \mathrm{L}\right)$ & $1032.00 \pm 128.44$ & $1139.20 \pm 152.14$ & $1127.80 \pm 35.53$ & $944.80 \pm 177.21$ \\
\hline & PT (s) & $7.80 \pm 0.32$ & $7.92 \pm 0.25$ & $7.80 \pm 0.19$ & $8.20 \pm 0.32 * \uparrow$ \\
\hline & APTT (s) & $16.80 \pm 1.65$ & $17.14 \pm 0.87$ & $18.18 \pm 1.67$ & $21.36 \pm 2.27^{\star \star \uparrow}$ \\
\hline \multirow[t]{3}{*}{$28 d$} & $\operatorname{RBC}\left(10^{12} / \mathrm{L}\right)$ & $7.10 \pm 0.30$ & $6.94 \pm 0.20$ & $6.82 \pm 0.24$ & $6.69 \pm 0.31 * \downarrow$ \\
\hline & $\mathrm{Hgb}(\mathrm{g} / \mathrm{L})$ & $137.20 \pm 8.04$ & $134.00 \pm 4.47$ & $129.80 \pm 4.66$ & $127.00 \pm 5.00^{\star} \downarrow$ \\
\hline & Hct (\%) & $39.54 \pm 1.69$ & $38.92 \pm 1.56$ & $37.46 \pm 0.92 \star \downarrow$ & $36.80 \pm 1.15^{\star \star} \downarrow$ \\
\hline
\end{tabular}


Table 5

Summary of clinical chemistry data (mean $\pm S D$, female, $n=5$ )

\begin{tabular}{|c|c|c|c|c|c|}
\hline $\begin{array}{l}\text { Time } \\
\text { group }\end{array}$ & Parameters & $\mathrm{C}$ & $\mathrm{L}$ & $M$ & $\mathrm{H}$ \\
\hline \multirow[t]{13}{*}{$3 d$} & ALT (U/L) & $21.28 \pm 3.05$ & $23.28 \pm 3.72$ & $23.18 \pm 8.12$ & $16.10 \pm 5.07$ \\
\hline & AST (U/L) & $104.84 \pm 8.80$ & $115.46 \pm 22.12$ & $98.20 \pm 9.96$ & $71.84 \pm 25.75^{\star} \downarrow$ \\
\hline & $\operatorname{ALP}(\mathrm{U} / \mathrm{L})$ & $159.54 \pm 37.44$ & $191.78 \pm 26.40$ & $143.12 \pm 29.25$ & $116.14 \pm 26.79 * \downarrow$ \\
\hline & $\mathrm{Y}-\mathrm{GT}(\mathrm{U} / \mathrm{L})$ & $0.75 \pm 0.17$ & $0.93 \pm 0.42$ & $0.72 \pm 0.19$ & $0.55 \pm 0.22$ \\
\hline & $\mathrm{TP}(\mathrm{g} / \mathrm{L})$ & $51.72 \pm 2.19$ & $49.78 \pm 1.80$ & $49.68 \pm 1.27$ & $41.94 \pm 4.52^{\star \star} \downarrow$ \\
\hline & $\operatorname{ALB}(\mathrm{g} / \mathrm{L})$ & $39.52 \pm 2.33$ & $38.56 \pm 0.78$ & $39.00 \pm 1.06$ & $38.76 \pm 2.30$ \\
\hline & GLU (mmol/L) & $6.48 \pm 0.64$ & $6.54 \pm 0.28$ & $6.42 \pm 0.49$ & $6.57 \pm 0.48$ \\
\hline & $\mathrm{CHOL}(\mathrm{mmol} / \mathrm{L})$ & $1.57 \pm 0.22$ & $1.39 \pm 0.07$ & $1.23 \pm 0.33$ & $1.09 \pm 0.44^{\star} \downarrow$ \\
\hline & $\mathrm{TG}(\mathrm{mmol} / \mathrm{L})$ & $0.14 \pm 0.07$ & $0.14 \pm 0.03$ & $0.11 \pm 0.03$ & $0.07 \pm 0.03^{\star} \downarrow$ \\
\hline & $\mathrm{Ca}^{2+}(\mathrm{mmol} / \mathrm{L})$ & $2.37 \pm 0.04$ & $2.34 \pm 0.07$ & $2.41 \pm 0.04$ & $2.72 \pm 0.20^{\star *} \uparrow$ \\
\hline & IP (mmol/L) & $2.46 \pm 0.17$ & $2.50 \pm 0.17$ & $2.33 \pm 0.19$ & $2.33 \pm 0.23$ \\
\hline & $\mathrm{Na}^{+}(\mathrm{mmol} / \mathrm{L})$ & $142.48 \pm 1.31$ & $142.76 \pm 1.10$ & $142.66 \pm 1.46$ & $147.18 \pm 3.08^{\star \star \uparrow}$ \\
\hline & $\mathrm{K}^{+}(\mathrm{mmol} / \mathrm{L})$ & $4.10 \pm 0.23$ & $3.96 \pm 0.21$ & $4.02 \pm 0.23$ & $3.57 \pm 0.18^{\star \star} \downarrow$ \\
\hline \multirow[t]{8}{*}{$7 d$} & $\operatorname{ALT}(\mathrm{U} / \mathrm{L})$ & $23.16 \pm 3.92$ & $21.30 \pm 3.79$ & $21.70 \pm 5.26$ & $16.06 \pm 2.88^{\star} \downarrow$ \\
\hline & AST (U/L) & $110.90 \pm 21.02$ & $100.70 \pm 16.41$ & $97.76 \pm 27.90$ & $63.26 \pm 4.60^{\star \star} \downarrow$ \\
\hline & $\operatorname{ALP}(\mathrm{U} / \mathrm{L})$ & $137.02 \pm 26.49$ & $152.30 \pm 46.54$ & $133.22 \pm 43.71$ & $127.86 \pm 55.40$ \\
\hline & $\mathrm{GLU}(\mathrm{mmol} / \mathrm{L})$ & $7.20 \pm 0.47$ & $6.77 \pm 0.51$ & $6.54 \pm 0.33^{\star} \downarrow$ & $7.15 \pm 0.56$ \\
\hline & CREA $(\mu \mathrm{mol} / \mathrm{L})$ & $27.20 \pm 4.15$ & $26.40 \pm 3.13$ & $34.20 \pm 3.90 * \star \uparrow$ & $26.40 \pm 1.52$ \\
\hline & $\mathrm{Ca}^{2+}(\mathrm{mmol} / \mathrm{L})$ & $2.39 \pm 0.07$ & $2.36 \pm 0.03$ & $2.36 \pm 0.04$ & $2.52 \pm 0.11^{\star \star} \uparrow$ \\
\hline & IP (mmol/L) & $2.44 \pm 0.08$ & $2.57 \pm 0.09$ & $2.65 \pm 0.13^{*} \uparrow$ & $2.52 \pm 0.20$ \\
\hline & $\mathrm{Na}^{+}(\mathrm{mmol} / \mathrm{L})$ & $144.12 \pm 1.69$ & $144.76 \pm 1.35$ & $143.74 \pm 0.65$ & $145.94 \pm 1.04 * \uparrow$ \\
\hline $28 d$ & $\operatorname{ALP}(\mathrm{U} / \mathrm{L})$ & $104.08 \pm 28.73$ & $115.76 \pm 51.01$ & $84.42 \pm 15.01$ & $91.24 \pm 32.89$ \\
\hline $90 d$ & $\operatorname{ALP}(\mathrm{U} / \mathrm{L})$ & $66.28 \pm 29.45$ & $69.56 \pm 18.64$ & $42.60 \pm 9.34$ & $40.64 \pm 5.74^{\star} \downarrow$ \\
\hline
\end{tabular}

Gross pathology

3 days after injection, scanty ascites were observed from the rats of high-dose group. Figure 4 presents the morphological appearance of a liver obtained from high-dose group, which, compared with that of the control group, shows darker red and more obvious veins. SCMC-induced liver congestion is considered to be responsible for the change of liver color and veins. The livers in $28 \mathrm{~d}$ group with high-dose injection were without any evident macroscopic lesion, suggesting the gradually recovering of livers with time extending. Similar reactions were also observed in spleen of high-dose group. Meanwhile, such phenomena were seldom observed in medium- and low-dose group. Moreover, the necropsies of the dead rats were conducted, showing large amount of scanty ascites and dark color of the livers and spleens.

Table 6 compared some selected organ coefficients of four dose groups over time. As can be seen, high-dose SCMC induced the spleen coefficients increase of male rats and liver coefficients increase of female rats 28 days after injection while coefficients of liver, spleen, adrenal and kidneys of female rats were also increased in $90 \mathrm{~d}$ group compared with that of the control group. 
Table 6

Summary of organ coefficients (mean $\pm S D, n=5$ )

\begin{tabular}{|c|c|c|c|c|c|}
\hline Group & Organs & Control & $\mathrm{L}$ & $M$ & $\mathrm{H}$ \\
\hline \multirow{4}{*}{$\begin{array}{l}28 \mathrm{~d} \\
\text { (male) }\end{array}$} & liver & $2.797 \pm 0.201$ & $2.803 \pm 0.219$ & $3.046 \pm 0.248$ & $2.941 \pm 0.088^{\ddagger}$ \\
\hline & spleen & $0.188 \pm 0.021$ & $0.190 \pm 0.013$ & $0.192 \pm 0.022$ & $0.224 \pm 0.035^{\ddagger \star} \uparrow$ \\
\hline & adrenal & $0.015 \pm 0.003$ & $0.014 \pm 0.001$ & $0.014 \pm 0.002$ & $0.014 \pm 0.001^{\ddagger}$ \\
\hline & kidneys & $0.771 \pm 0.021$ & $0.752 \pm 0.077$ & $0.769 \pm 0.071$ & $0.719 \pm 0.012^{\ddagger}$ \\
\hline \multirow{4}{*}{$\begin{array}{l}28 d \\
\text { (female) }\end{array}$} & liver & $2.792 \pm 0.187$ & $2.976 \pm 0.290$ & $2.908 \pm 0.320$ & $3.217 \pm 0.156 * \uparrow$ \\
\hline & spleen & $0.237 \pm 0.037$ & $0.207 \pm 0.015$ & $0.232 \pm 0.055$ & $0.225 \pm 0.035$ \\
\hline & adrenal & $0.028 \pm 0.005$ & $0.026 \pm 0.004$ & $0.024 \pm 0.003$ & $0.028 \pm 0.005$ \\
\hline & kidneys & $0.740 \pm 0.075$ & $0.784 \pm 0.034$ & $0.741 \pm 0.068$ & $0.750 \pm 0.024$ \\
\hline \multirow{4}{*}{$\begin{array}{l}90 d \\
\text { (female) }\end{array}$} & liver & $2.587 \pm 0.166$ & $2.710 \pm 0.143$ & $2.673 \pm 0.221$ & $2.931 \pm 0.249 * \uparrow$ \\
\hline & spleen & $0.164 \pm 0.026$ & $0.176 \pm 0.020$ & $0.165 \pm 0.011$ & $0.202 \pm 0.031 * \uparrow$ \\
\hline & adrenal & $0.018 \pm 0.001$ & $0.025 \pm 0.004^{* *} \uparrow$ & $0.021 \pm 0.004$ & $0.023 \pm 0.004 * \uparrow$ \\
\hline & kidneys & $0.658 \pm 0.066$ & $0.723 \pm 0.021$ & $0.700 \pm 0.053$ & $0.735 \pm 0.041 * \uparrow$ \\
\hline
\end{tabular}

Histopathology

Table 7 presents the proportions of main histopathology findings and corresponding severities obtained from four time groups injected with different doses of SCMC. It is clear that, for $3 \mathrm{~d}$ group with high-dose injection, vacuolization was observed in multiple organs including spleen, liver and pancreas, whereas, 7 days after injection, vacuolated adrenal was noted and the reaction severities of spleen and liver increased. As for $28 \mathrm{~d}$ group, vacuolization reactions of kidneys and uterus were induced by high-dose SCMC and that of spleen had an alleviation. 90 days after injection, while insignificant changes occurred to adrenal, kidneys and uterus, organs consist of spleen, liver and pancreas showed relieved reactions. Furthermore, when compared with high-dose group, the organs with medium dose of SCMC were not apparently changed except that, 7 days after injection, slight reactions were occurred in livers and adrenals, as shown in Table 7. Meanwhile, no histopathology findings of organs are induced by low-dose SCMC.

As the most important immune organ of mononuclear phagocyte system, spleen shows strong reaction with high-dose of SCMC and its time-dependence is demonstrated in Fig. 5, from which the most severe vacuolization was observed in 7d group, as shown in Fig. 5(b). The reactions of spleens in 7d group compared with the control group are exhibit in Fig. 6. As can be seen from Fig. 6(a) and (b) diffuse reaction occurred in red pulp compared with the control group. Zooming-in further evidences that vacuoles are macrophages that have phagocytized foreign particles, as shown in Fig. 6(c) and (d). A representative macrophage is marked by the red arrow in Fig. 6(d).

Figure 7 and 8 show the histopathologic appearances of livers of 3d and 7d groups, respectively. As can be seen from Fig. 7, slight congestion was observed in the liver of rats in high-dose group 3 days after administration. Furthermore, the changes of livers are found to possess strongest dose dependence, as shown in Fig. 8. It is clear that, compared with the control group, the livers in high-dose group suffers from remarkable vacuolization. Along with the dosage of SCMC decreasing to medium, the vacuolization of livers significantly decreased and, eventually, intact livers are observed in low-dose group.

The high-dose SCMC related reaction of pancreas in 7d group are shown in Fig. 9(a), while that of adrenal, kidneys and uterus obtained from 90d groups are illustrated in Fig. 9(b)-9(c), respectively. It is found that, in these organs, vacuolization is also induced by absorbed SCMC.

As aforementioned, 3 rats died in the initial 2 days after high-dose injection of SCMC, whose organs including thymus, spleen and kidneys are shown in Fig. 10. Comparing with the control group, severe apoptosis and decrease of lymphocytes were observed in thymus of dead rats, which are presented in Fig. 10(a) and 10(b). Meanwhile, as shown in Fig. 10(c) and 10(d), medium decrease of lymphocytes and increase of macrophages were noted in spleen. As for other organs, taking kidneys for instance (see Fig. 10(e) and 10(f)), while infiltration of macrophages and polymorphic nucleus WBC were observed in interstitium, light blue-stained substances considered to be absorbed SCMC were found emerged in these regions. These phenomena are probably responsible for the death of the rats. 
Table 7

Summary of the incidence proportion and severities of vacuolization

\begin{tabular}{|c|c|c|c|c|c|c|c|c|c|c|c|c|c|c|c|c|c|}
\hline \multirow[t]{3}{*}{ Time } & \multirow{3}{*}{$\begin{array}{l}\text { Proportion } \\
\text { and } \\
\text { severity }\end{array}$} & \multirow{2}{*}{\multicolumn{2}{|c|}{$\begin{array}{l}\mathrm{L} \\
/\end{array}$}} & \multicolumn{4}{|l|}{$M$} & \multicolumn{10}{|l|}{$\mathrm{H}$} \\
\hline & & & & \multicolumn{2}{|c|}{ Adrenal } & \multicolumn{2}{|c|}{ Liver } & \multicolumn{2}{|c|}{ Spleen } & \multicolumn{2}{|l|}{ Liver } & \multicolumn{2}{|c|}{ Pancreas } & \multicolumn{2}{|c|}{ Adrenal } & \multicolumn{2}{|c|}{ Kidneys } \\
\hline & & $M$ & $\mathrm{~F}$ & $M$ & $\mathrm{~F}$ & $M$ & $\mathrm{~F}$ & $M$ & $\mathrm{~F}$ & M & $\mathrm{F}$ & $M$ & $\mathrm{~F}$ & $M$ & $\mathrm{~F}$ & $M$ & $\mathrm{~F}$ \\
\hline \multirow[t]{2}{*}{$3 d$} & proportion & / & / & I & I & / & / & $5 / 5$ & $4 / 5$ & $5 / 5$ & $4 / 5$ & $1 / 5$ & $3 / 5$ & / & / & / & / \\
\hline & severity & I & I & / & / & I & I & ++ & ++ & + & + & + & + & I & I & / & / \\
\hline \multirow[t]{2}{*}{$7 d$} & proportion & l & I & $2 / 5$ & I & $2 / 5$ & I & $4 / 4$ & $5 / 5$ & $4 / 4$ & $5 / 5$ & $4 / 4$ & $4 / 5$ & $4 / 4$ & $4 / 5$ & I & I \\
\hline & severity & I & I & + & I & + & I & +++ & +++ & ++ & ++ & + & + & + & + & I & I \\
\hline \multirow[t]{2}{*}{$28 d$} & proportion & / & / & I & $1 / 5$ & / & / & $3 / 3$ & $5 / 5$ & 33 & $5 / 5$ & $3 / 3$ & $4 / 5$ & $1 / 3$ & $4 / 5$ & $1 / 3$ & $3 / 5$ \\
\hline & severity & / & / & / & + & / & / & ++ & ++ & ++ & ++ & + & + & + & + & + & + \\
\hline \multirow[t]{2}{*}{$90 d$} & proportion & / & / & I & $1 / 5$ & I & / & $1 / 5$ & I & $4 / 5$ & $5 / 5$ & / & $2 / 5$ & $4 / 5$ & $5 / 5$ & $3 / 5$ & $5 / 5$ \\
\hline & severity & / & / & I & + & / & / & + & / & + & + & / & + & + & + & + & + \\
\hline
\end{tabular}

\section{Discussions}

Systemic toxicity evaluation for SCMC after intraperitoneal application

In our work, the rats show adverse reactions to SCMC at the dose of $320 \mathrm{mg} / \mathrm{kg}$ and several rats (less than $50 \%$ ) died at the dose of $2000 \mathrm{mg} / \mathrm{kg}$, which demonstrates that the minimal lethal dose (MLD) of intraperitoneally applied SCMC to rats is higher than $320 \mathrm{mg} / \mathrm{kg}$ and lethal dose $50 \%$ (LD50) is higher than $2000 \mathrm{mg} / \mathrm{kg}$. Compared with the results of previous oral studies that animals show no visible reactions to SCMC at the dose of 10-20 $\mathrm{g} / \mathrm{kg} / \mathrm{d}$ [2, 3, 16], there are obvious differences in this intraperitoneal study. However, because the adverse reactions do not cause significant irreversible injury to organ tissues or cells and the dose leading to adverse reactions is comparatively high, SCMC is still a safe material when it is used as anti-adhesion or hemostatic material in the abdominal cavity below the dose that can induce adverse effects.

Analyzation of the mechanism behind the adverse effects by intraperitoneal administration of SCMC

As is well known, the same as human, due to the absence of $\beta$-lactamases in the body, the rats are unable to digest macromolecule SCMC into glucose. Therefore, after being administrated into the peritoneal cavity of the rat, SCMC can be slowly absorbed as macromolecule into peritoneal capillaries and then transported into the interstitium of spleen, liver and pancreas. In these organs, along with the increase of SCMC, owing to the viscosity of SCMC, blood circulation and substances transportation are blocked. Meanwhile, the SCMC in these organs is recognized as a foreign body by mononuclear phagocyte system $[19,20]$ which triggers a nonspecific immune response. During this process, monocyte-macrophages proliferate and gather to these organs to phagocytize and dispose SCMC, which might aggravate the blocking phenomena. Further, along with the absorption of SCMC into blood, plasma osmotic pressure can be increased, leading to the increase of blood volume. As a result, slight congestion is induced in hepatic sinusoids while liver synthesized and secreted substances including clotting factors, liver enzymes, proteins and lipids are decreased [21]. In spleen, these aforementioned phenomena lead to congestion and enhance its retention effects to blood cells, which induce the decreases of RBC and platelets [20, 22]. Similarly, in pancreas, the synthesis and secretion of insulin are inhibited, inducing the increase of blood glucose. Additionally, $\mathrm{Na}^{+}$is absorbed into the blood along with the absorption of SCMC, which subsequently causes the changes of other ions including $\mathrm{Ca}^{2+}, \mathrm{IP}$ and $\mathrm{K}^{+}$. With time extending, SCMC is completely absorbed into blood and decomposed gradually into smaller particles by macrophages until they can be excreted by kidneys and other organs, which is coincident with the reduction of adverse reactions over time observed in our work.

Reason for different systemic toxicity profile of SCMC applied following different routes

According to IS010993-11, absorption, distribution and metabolism of leachates from the device or its materials to parts of the body are inevitable processes that induce generalized effects, as well as organ and organ system effects [18]. As a macromolecule, SCMC can hardly be absorbed by the stomach and intestine into blood $[3,16]$. Hence, following oral route, even at the dose of $10-20 \mathrm{~g} / \mathrm{kg} / \mathrm{d}$, animals show no visible reactions to SCMC, which has been proved by previous studies $[2,3,16]$. However, along with the change of administration route to intraperitoneal injection, SCMC is exposed directly in the body and the body has to absorb it into blood, distribute it to organs, metabolize and then excrete it. As the dose increases to higher than $320 \mathrm{mg} / \mathrm{kg}$, SCMC cannot be disposed in time and it accumulates in blood and organs to result in the occurrence of a series of adverse effects. These results demonstrate that, for certain material, the systemic reactions might be different when its administration routes are changed, for instance, from oral to intraperitoneal route. In this regard, the systemic toxicity reactions should be sufficiently considered when the applications of biomaterials are extended.

Discussion of systemic toxicity test design for absorbable biomaterials

In our work, it is evidenced that the systemic reactions of the absorbable materials may possess remarkable dose dependence, which is expressed in adverse effects of body weight, clinical pathology and histopathology with high-dose injection and negligible effects induced by low-lose of SCMC. Such a dose effect is particularly evident in livers, for which medium dose leads to slight reactions. Furthermore, the investigations of systemic toxicity over time shows that the most significant reactions of clinical pathology and histopathology appear 3 and 7 days after injection, respectively, whereas 90 days after injection the

Page $9 / 24$ 
reactions were not obvious, which indicates the strong time dependence of the reactions and, hence, the irrationality of the aforementioned single treatment duration. Therefore, for the purpose of study design of the absorbable biomaterials such as SCMC, it is essential to take both dose and time effects into account, which pave a way for the establishment of guidelines for the systemic toxicity tests related to these materials.

\section{Conclusions}

Following intraperitoneal route, the systemic toxicity of SCMC are investigated thoroughly over dose and time, the results of which lead to the conclusion that intraperitoneal injection of SCMC at the dose of $2000 \mathrm{mg} / \mathrm{kg}$ can induce obvious reactions including acute inflammatory response, decreases of RBC and platelets, adverse effects on liver function and glucose metabolism, electrolyte disturbance as well as vacuolization in multiple organs. These reactions are found varied with time extending and virtually disappeared 90 days after injection. The medium-dose(320 mg/kg) group shows slight reactions while lowdose $(50 \mathrm{mg} / \mathrm{kg}$ ) SCMC induces negligible effects. Therefore, SCMC should be used as anti-adhesion or hemostatic material in the abdominal cavity below the dose that can induce adverse effects. Additionally, these facts indicate that, when design a systemic toxicity study for absorbable materials, it is essential to take both dose- and time-dependent effects into account while simulating the clinical use in terms of administration route and dose frequency.

\section{Materials And Methods}

Animals

160 SD rats, 6-8 weeks old with half male and half female, were purchased from Beijing Vital River Laboratory Animal Technology Co., Ltd.

Materials

It is well known that, for practical applications, most of the SCMC intraperitoneal anti-adhesion and hemostasis medical devices were made with low viscosity

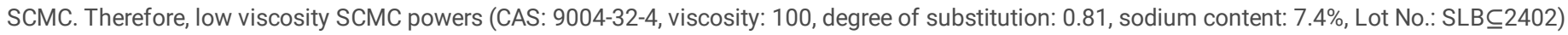
purchased from Sigma were used in our work.

Experimental procedures

According to their weight, rats were divided at random into 4 groups with each group composed of male and female in equal, represented as control group (C), low-dose group $(\mathrm{L})$, medium-dose group $(\mathrm{M})$ and high-dose group $(\mathrm{H})$. Rats of each dose group were then randomly divided into 4 time groups including 3 days (d), 7d, 28d and 90d group. The SCMC powders were dissolved in the sterile water for injection, forming the test solutions with the concentrations of $5 \mathrm{mg} / \mathrm{ml}, 32 \mathrm{mg} / \mathrm{ml}$ and $200 \mathrm{mg} / \mathrm{ml}$, respectively. These test solutions were intraperitoneally injected into the rats with the dose volume of $10 \mathrm{ml} / \mathrm{kg} \cdot \mathrm{BW}$, corresponding to the doses of $50 \mathrm{mg} / \mathrm{kg}$ for $\mathrm{L}, 320 \mathrm{mg} / \mathrm{kg}$ for $\mathrm{M}$ and $2000 \mathrm{mg} / \mathrm{kg}$ for H. Such doses were determined by the results of pre-experiments. Meanwhile, the control group was injected with the sterile water for injection with the same dose volume [23]. In order to simulate the clinic use, the SCMC solutions were intraperitoneally injected into rats all at once. During the clinical observation procedure, the rats were weighed weekly and observed daily for general health. Subsequently, 10 rats (half male and female) of each dose group were sacrificed respectively $3 d$, $7 d, 28 d$ and $90 \mathrm{~d}$ after injection in order to evaluate the time-dependence of systemic toxicity reactions of SCMC. At the day before necropsy, rats of each group were weighed and fasted overnight, and the anesthetization was implemented following intraperitoneal route with pentobarbital sodium at the dosage of $40 \mathrm{mg} / \mathrm{kg} \cdot \mathrm{BW}$. Blood samples for clinical pathology analyses were collected from abdominal aorta. Hematology and clinical chemistry parameters investigated in our work and corresponding abbreviations are shown in Table 8. After euthanizing by exsanguination while being anesthetized, a gross necropsy was performed in terms of the external surface of the body, all orifices, and the cranial, thoracic and abdominal cavities and their contents. Organs including testes/ovaries, uterus/epididymis, spleen, liver, adrenals, kidneys, thymus, heart and brain were weighed wet as soon as possible after dissection to obtain the organ coefficients (relative to body weight). These organs, along with stomach, intestine, pancreas, lung and thyroid gland were preserved in $10 \%$ formalin to form fixed tissues, which, ultimately, were embedded, sectioned and stained with hematoxylin-eosin for pathology analyses.

Table 8

Parameters and abbreviations of clinical pathology analyses

\begin{tabular}{|lll|}
\hline Hematology & Clinical chemistry analyses & Clinical chemistry analyses \\
\hline White blood cell (WBC) & Alanine amino transferase (ALT) & Urea (UREA) \\
\hline Red blood cell (RBC) & Aspartate amino transferase (AST) & Cholesterol (CHOL) \\
\hline Hemoglobin (Hgb) & Alkaline phosphatase (ALP) & Triglyceride (TG) \\
\hline Hematocrit (Hct) & Y-glutamyl transpeptidase $(\mathrm{Y}-\mathrm{GT})$ & Calcium ion $\left(\mathrm{Ca}^{2+}\right)$ \\
\hline Platelet (PLT) & Total protein (TP) & Inorganic Phosphorus (IP) \\
\hline Prothrombin time (PT) & Albumin (ALB) & Sodion $\left(\mathrm{Na}^{+}\right)$ \\
\hline Activated partial thromboplastin & Glucose (GLU) & Kalium ion $\left(\mathrm{K}^{+}\right)$ \\
\hline time (APTT) & Creatinine (CREA) & Chloridion $\left(\mathrm{Cl}^{-}\right)$ \\
\hline
\end{tabular}

\section{Data analyses}


Data from male and female were analyzed separately with SPSS17.0 statistical software (SPSS, US, IBM). Calculations resulting in probability (P) values less than 0.05 were considered to be statistically significant.

\section{Declarations}

\section{Ethics approval and consent to participate}

All procedures for animal experiments were performed in accordance with Institutional Animal Care and Use Committee Protocols.

\section{Consent for publication}

All the authors of the paper approved the publication of the article.

\section{Availability of data and material}

Data related to the current study are available from the corresponding author on reasonable request.

\section{Competing interests}

All authors declare that they have no actual or potential competing of interest.

\section{Funding}

This work was supported by the National Key Research and Development Program (2016YFC1103205) and Science and Technology Fund of Shandong Province (2017GSF218004).

\section{Authors' contributions}

CGF, CHL, LH and YPS, conceived and designed the experiments; CGF, GXC, XDL, LKS, WSJ, FYZ and MX performed the experiments; CGF, CHL and LH analyzed the data; CFG, ZLZ and XXG contributed reagents/materials/analysis tools; CGF, CHL and LH wrote the paper. All authors read and approved the final manuscript.

\section{Acknowledgements}

Not applicable.

\section{References}

1. Aisi W, Gongmin S. Study on Optimum Technological Conditions of Preparation of CMC Na. Bull Sci Tech. 1998;3:193-8.

2. Mondal MI, Yeasmin MS. Toxicity study of food-grade carboxymethyl cellulose synthesized from maize husk in Swiss albino mice. Int J Biol Macromol. 2016;92:965-71.

3. Bär A, Til HP, Timonen M. Subchronic oral toxicity study with regular and enzymatically depolymerized sodium carboxymethyl cellulose in rats. Food Chem Toxicol. 1995;33:909-17.

4. Berdah SV, Mariette C, Denet C, et al. A multicentre, randomised, controlled trial to assess the safety, ease of use, and reliability of hyaluronic acid/carboxymethylcellulose powder adhesion barrier versus no barrier in colorectal laparoscopic surgery. Trials. 2014;15:413.

5. Corrales F, Corrales M, Schirmer CC. Preventing intraperitoneal adhesions with vitamin E and sodium hyaluronate/ carboxymethyl cellulose: a comparative study in rats. Acta Cir Bras. 2008;23:36-41.

6. Yelimlies B, Alponat A, Cubukcu A, et al. Carboxymethylcellulose coated visceral face of polypropylene mesh prevents adhesion without impairing wound healing in incisional hernia model in the rats. Hernia. 2003;7:130-3.

7. Vrijland WW, Tseng LN, Eijkman HJ, et al. Fewer intraperitoneal adhesions with use of hyaluronic acid-carboxymethyl cellulose membrane: a randomized clinical trial. Ann Surg. 2002;235:193-9.

8. Wurster SH, Bonet V, Mayberry A, et al. Intraperitoneal sodium carboxymethylcellulose administration prevents reformation of peritoneal adhesions following surgical lysis. J Surg Res. 1995;59:97-102.

9. Hemadeh $\mathrm{O}$, Chilukuri S, Bonet V, et al. Prevention of peritoneal adhesions by administration of sodium carboxymethyl cellulose and oral vitamin E. Surg. 1993;114:907-10.

10. Sousa AA, Petroianu A, Trapiello Neto V, et al. Effect of sodium carboxymethyl cellulose and methyl prednisolone on the healing of jejunal anastomoses in rats. Braz J of Med Biol Res. 2001;34:519-23.

11. Yaacobi Y, Israel AA, Goldberg EP. Prevention of postoperative abdominal adhesions by tissue precoating with polymer solutions. J Surg Res. 1993;55:422-6.

12. Wei L, Lingshuang W, Weiqing S. Study on the clinical application and mechanism of cellulose hemostatic materials. Contemp Med Symp. 2019;17:13-5.

13. Tomizawa Y. Clinical benefits and risk analysis of topical hemostats: a review. J Artif Organs. 2005;8:137.

14. Mei Z. Investigation on hemostatic mechanism of soluble hemostatic fabric. J Tex Res. 1997;18:268-72.

15. Galgut PN. Oxidized cellulose mesh:I. Biodegradable membrane in periodontal surgery. Biomaterials. 1990;11:561-4.

Page $11 / 24$ 
16. McElligott TF, Hurst EW. Long-term feeding studies of methylethyl cellulose ('Edifas' A) and sodium carboxymethylcellulose ('Edifas' B) in rats and mice. Food Cosmet Toxicol. 1968;6:449-60.

17. ISO 10993-1. 2018 Biological evaluation of medical devices-Part 1: Evaluation and testing within a risk management process.

18. ISO 10993-11. 2017 Biological evaluation of medical devices-Part 11: Tests for systemic toxicity.

19. Sage RJ, Chaffins ML, Kouba DJ. Granulomatous Foreign Body Reaction to Hyaluronic Acid: Report of a Case After Melolabial Fold Augmentation and Review of Management. Dermatol Surg. 2009;35:1696-700.

20. Haan JMMD, Kraal G. Innate Immune Functions of Macrophage Subpopulations in the Spleen. J Innate Immun. 2012;4:437-45.

21. Shivaraj G, Prakash B, et al. A review on laboratory liver function tests. Pan African Med J. 2009;3:17.

22. Mebius RE, Kraal G. Structure and function of the spleen. Nat Rev Immunol. 2005;5:606-16.

23. ISO 10993-12. 2012 Biological evaluation of medical devices-Part 12: Sample preparation and reference materials.

\section{Figures}

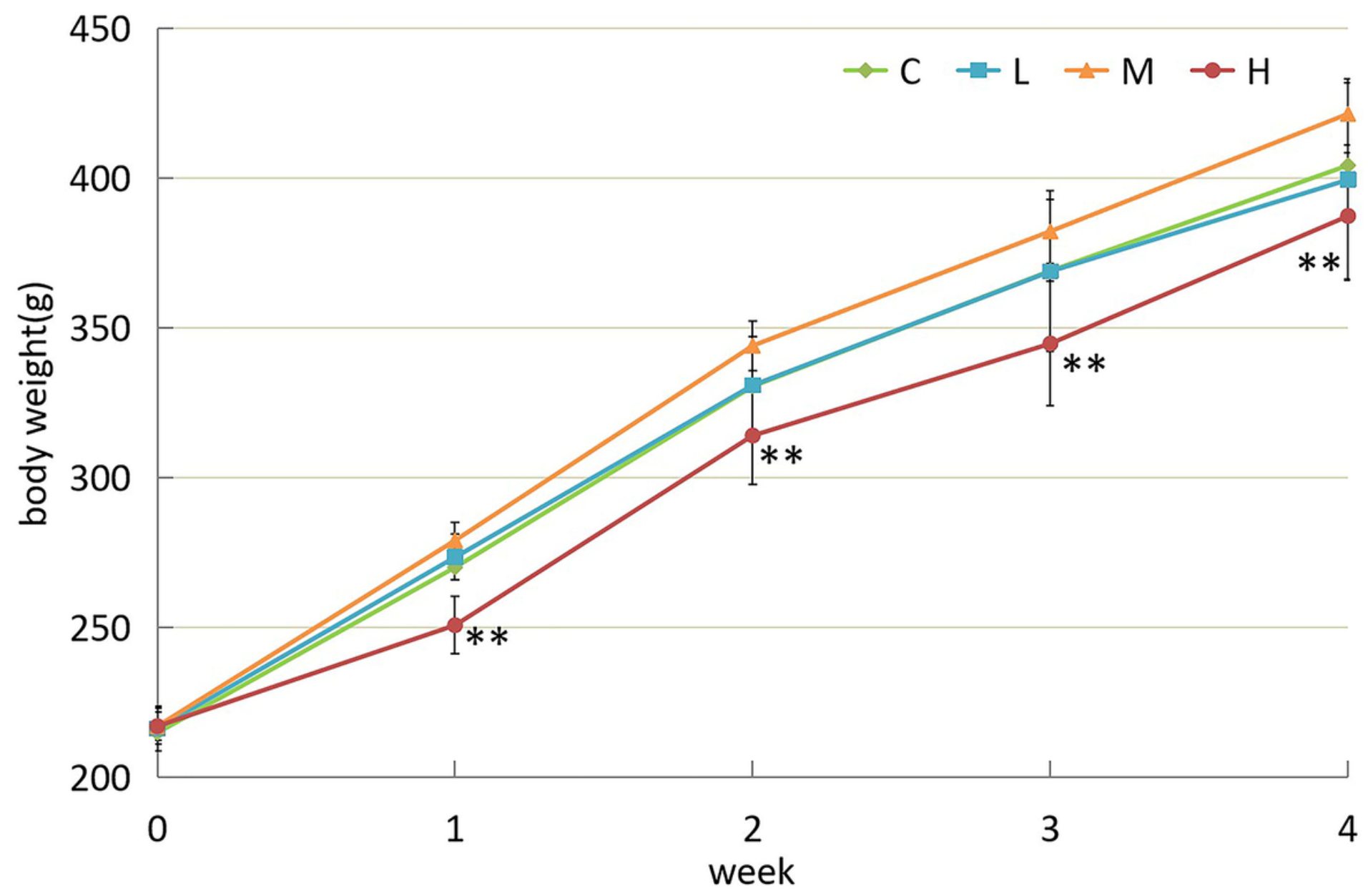

Figure 1

Dose- and time-dependence of MBWs of male rats in 28d group; ${ }^{\star * P} \llbracket 0.01$, compared to the control group 


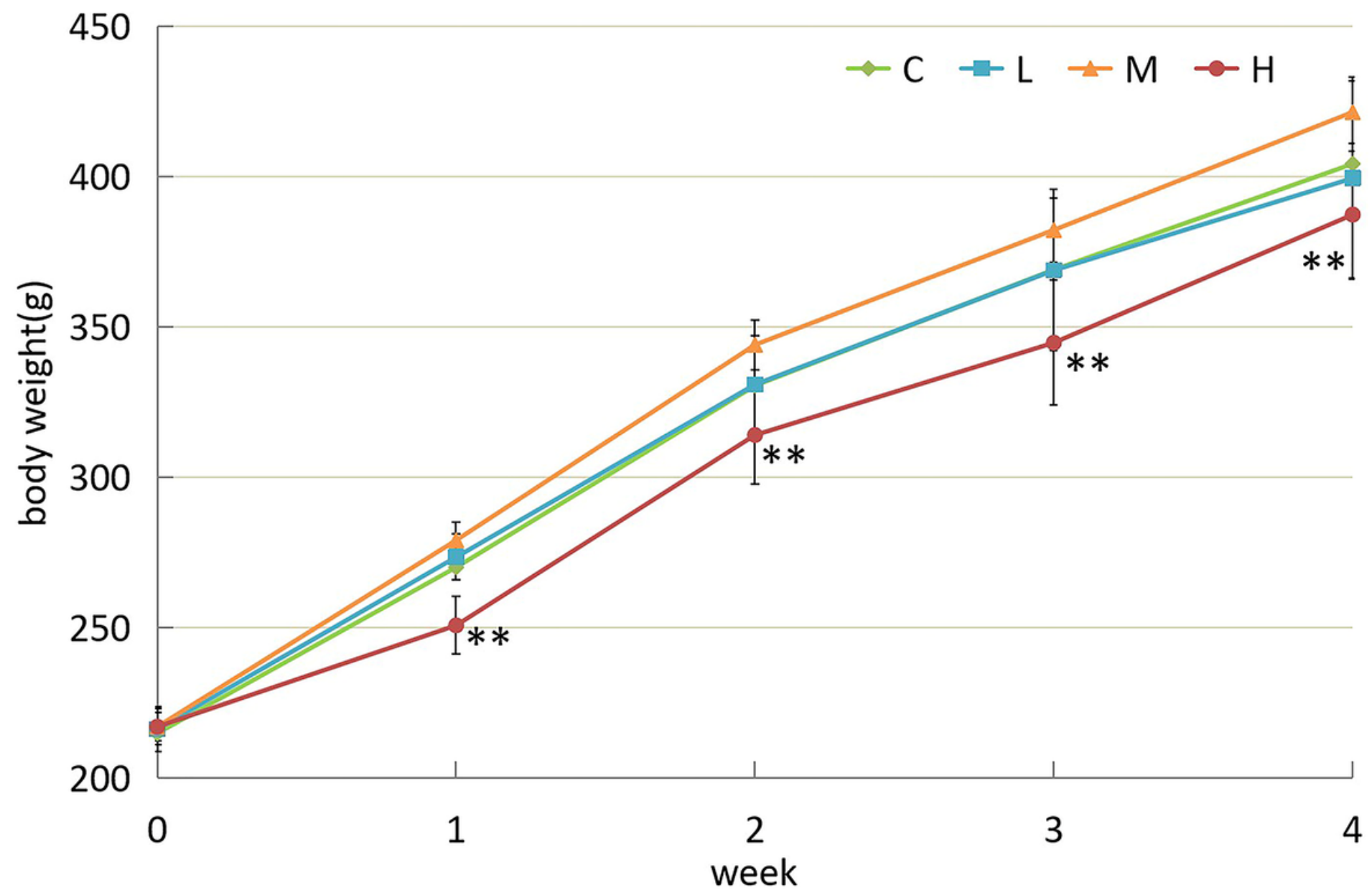

Figure 1

Dose- and time-dependence of MBWs of male rats in 28d group; **P $₫ 0.01$, compared to the control group

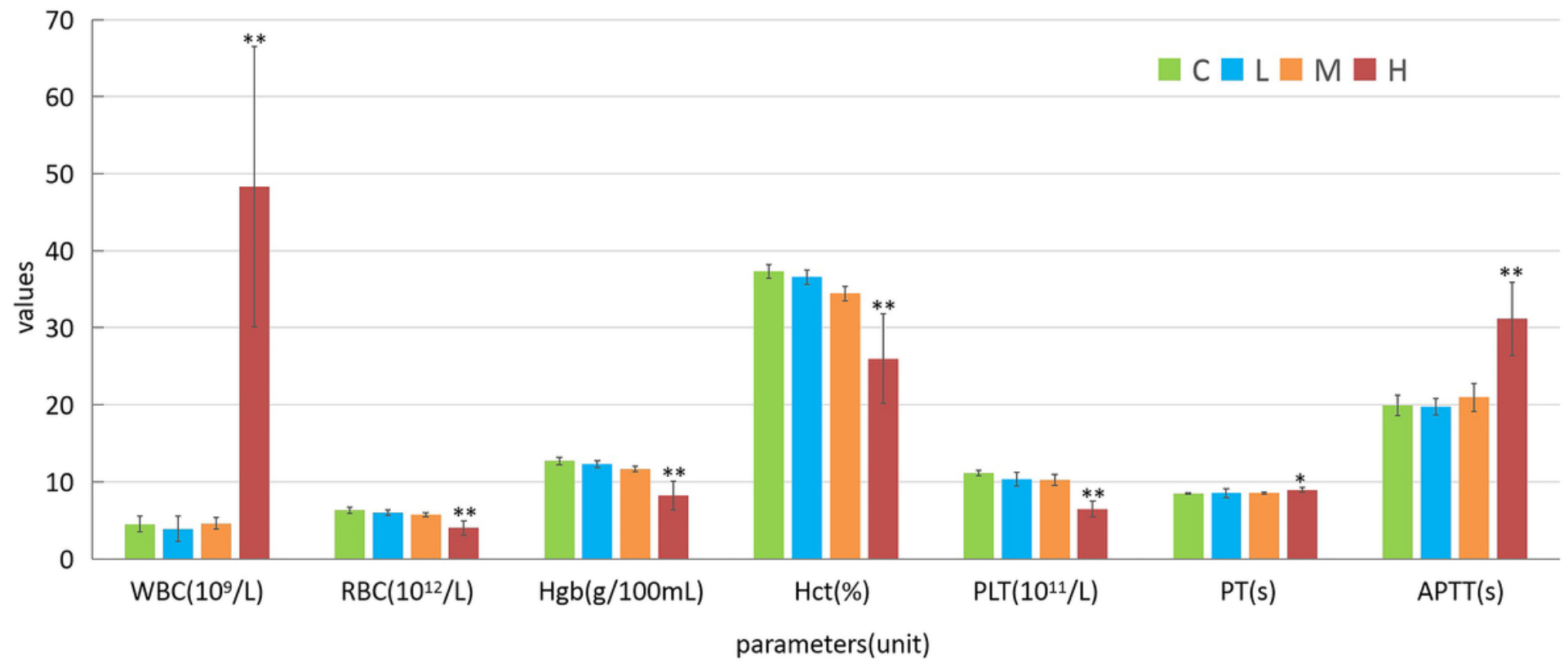

Figure 2

Hematology results of male rats in each dose group $3 \mathrm{~d}$ after injection; *Pख0.05 and ${ }^{*} \mathrm{P} \otimes 0.01$, compared to the control group 


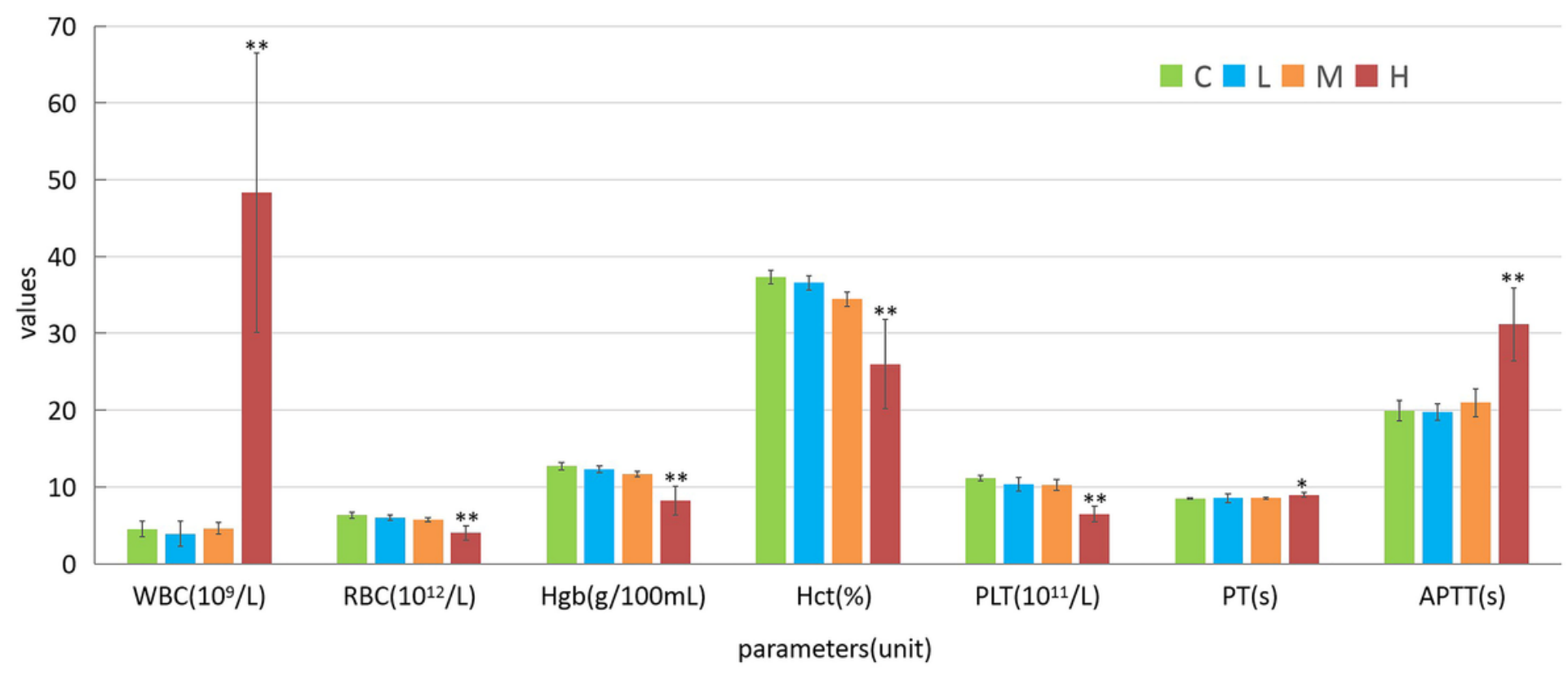

Figure 2

Hematology results of male rats in each dose group $3 \mathrm{~d}$ after injection; *P $₫ 0.05$ and $* * P \otimes 0.01$, compared to the control group

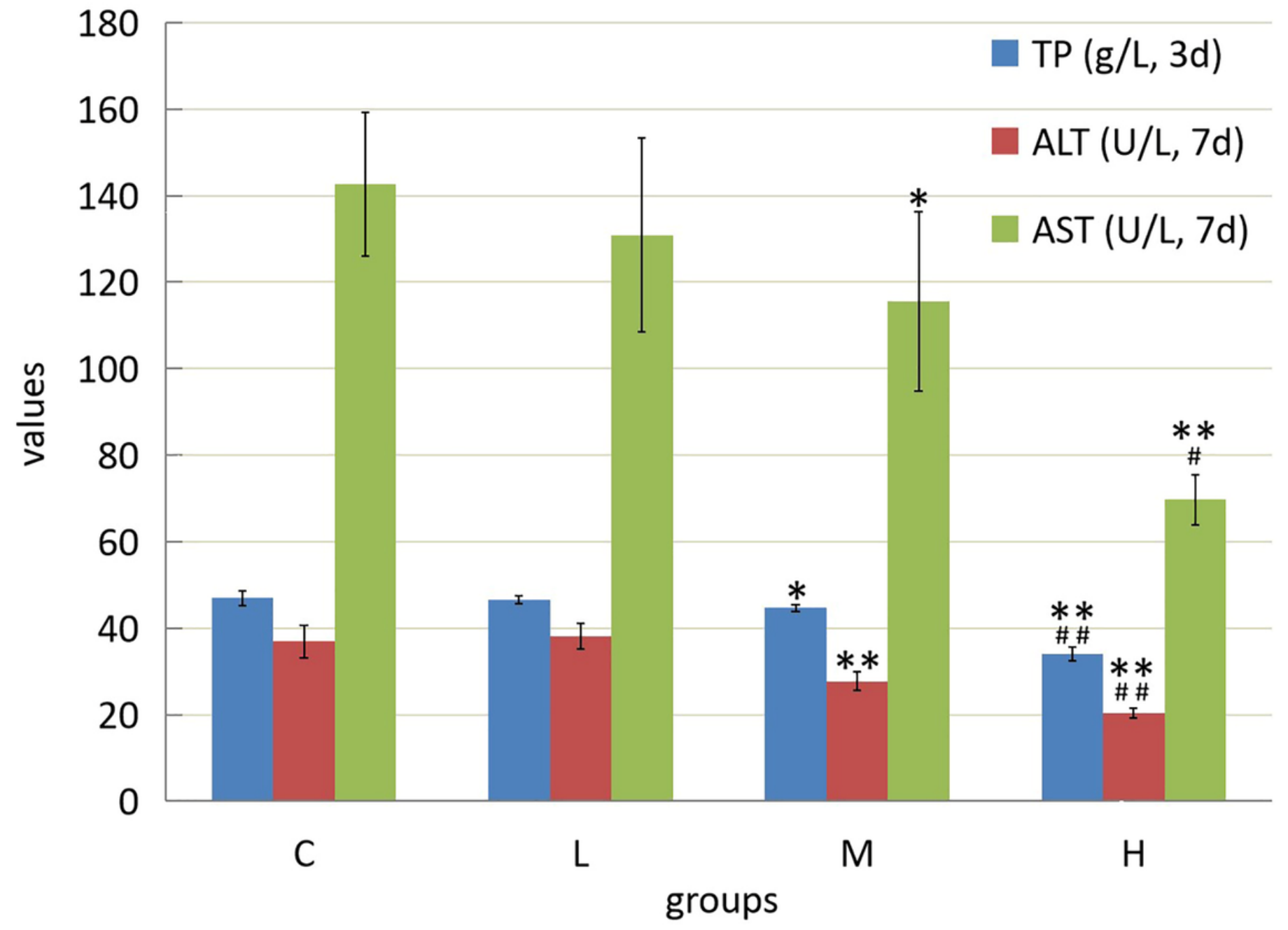

Figure 3

Comparison of TP, ALT and AST of male rats in four groups after injection;*Pख0.05 and **Pख0.01, compared to the control group; \#Pख0.05, \#\#Pख0.01, compared to the medium-dose group 


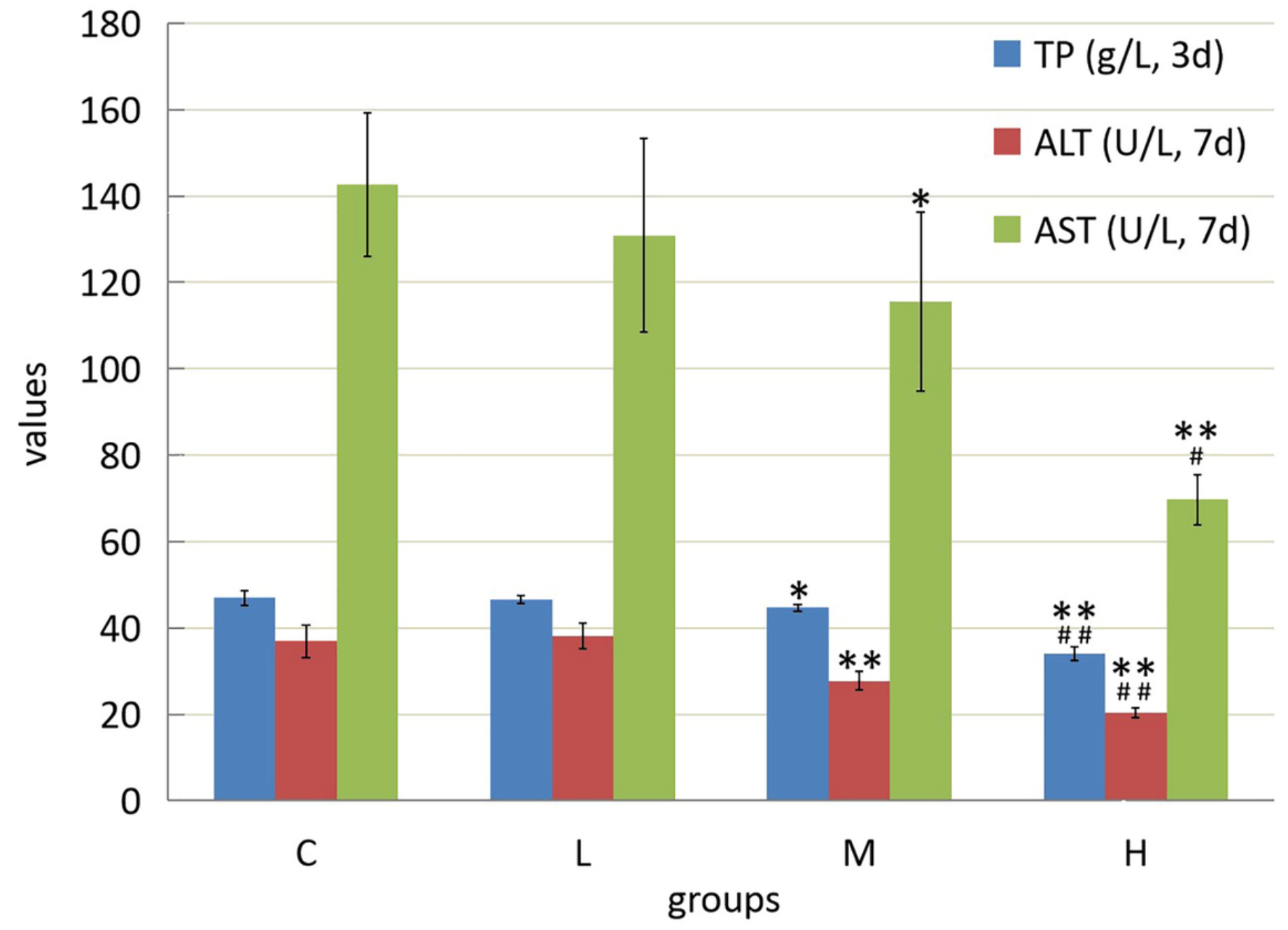

Figure 3

Comparison of TP, ALT and AST of male rats in four groups after injection;*Pख0.05 and **Pख0.01, compared to the control group; \#Pख0.05, \#\#Pख0.01, compared to the medium-dose group

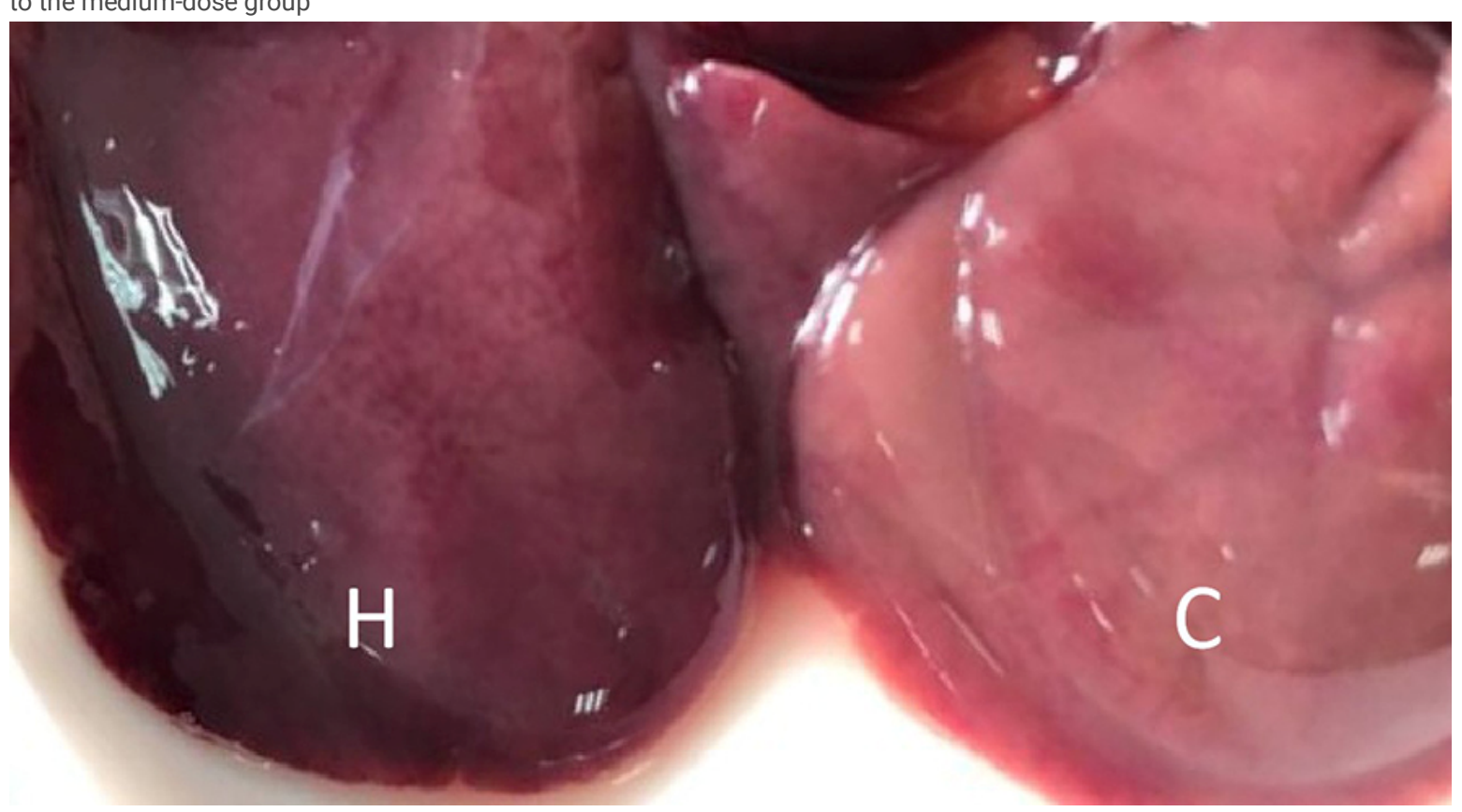

Figure 4 


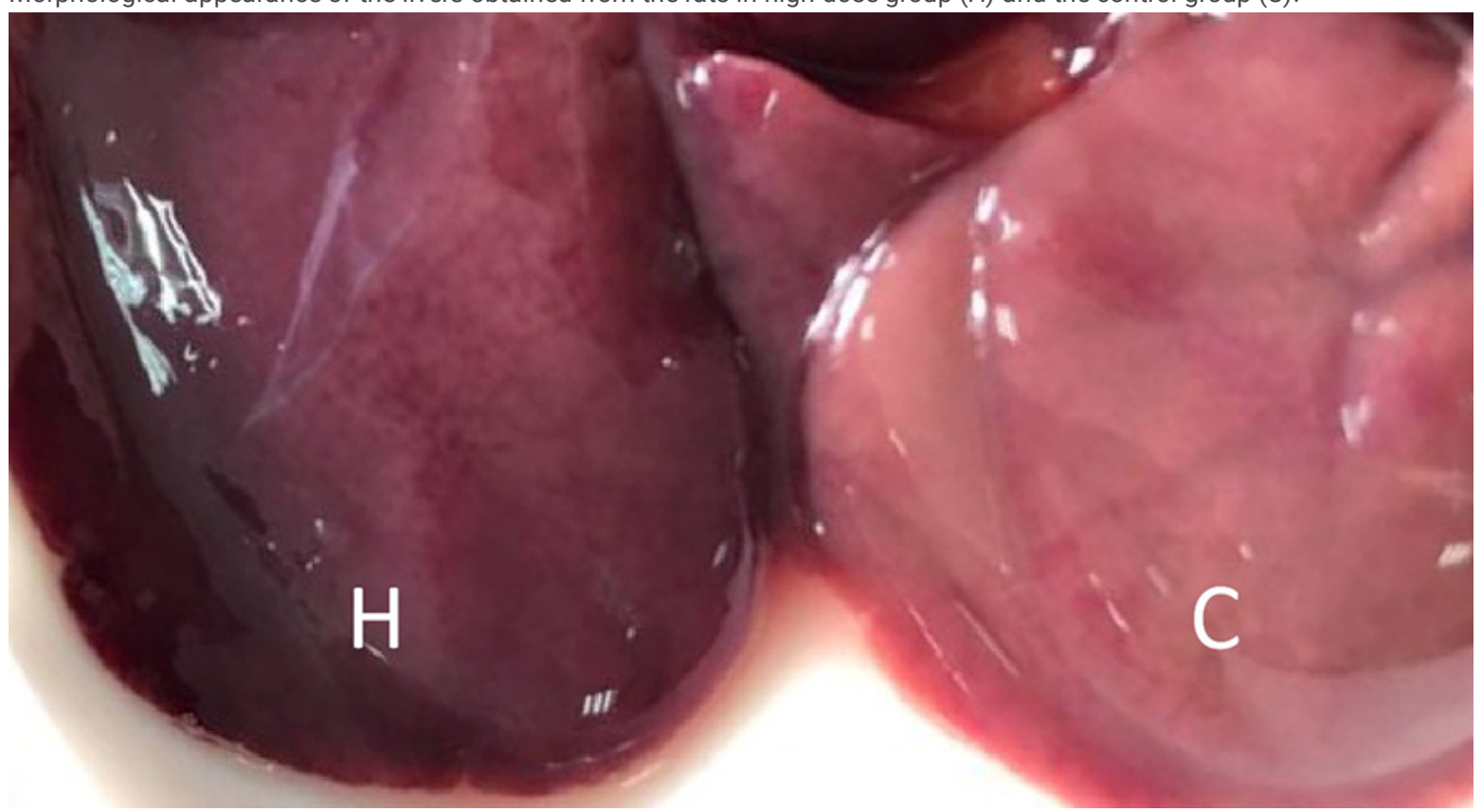

Figure 4

Morphological appearance of the livers obtained from the rats in high-dose group $(H)$ and the control group (C).

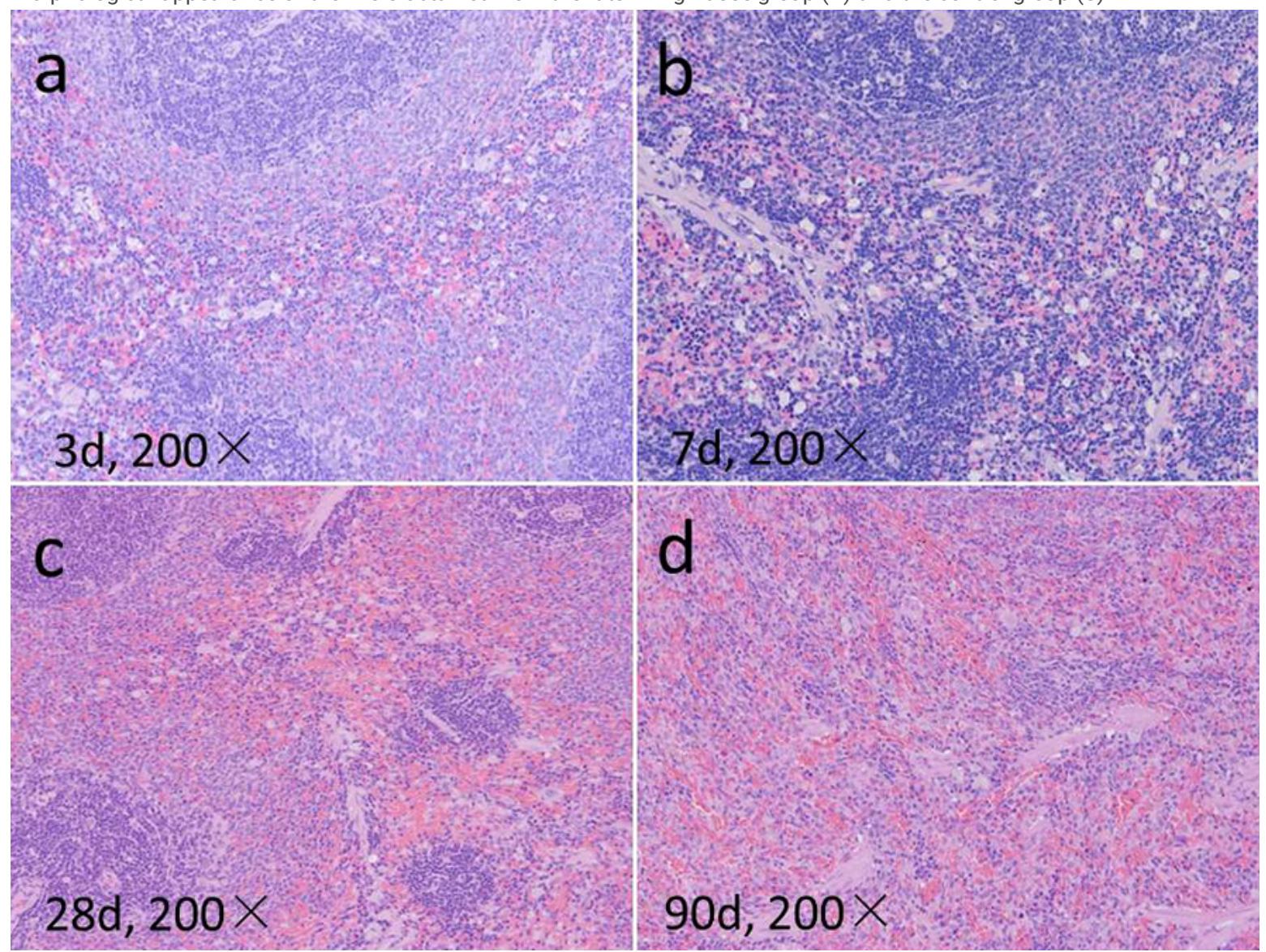

\section{Figure 5}

Time-dependence of reaction in spleen of high-dose group; mild, medium, mild and slight reactions are observed from a-d respectively 


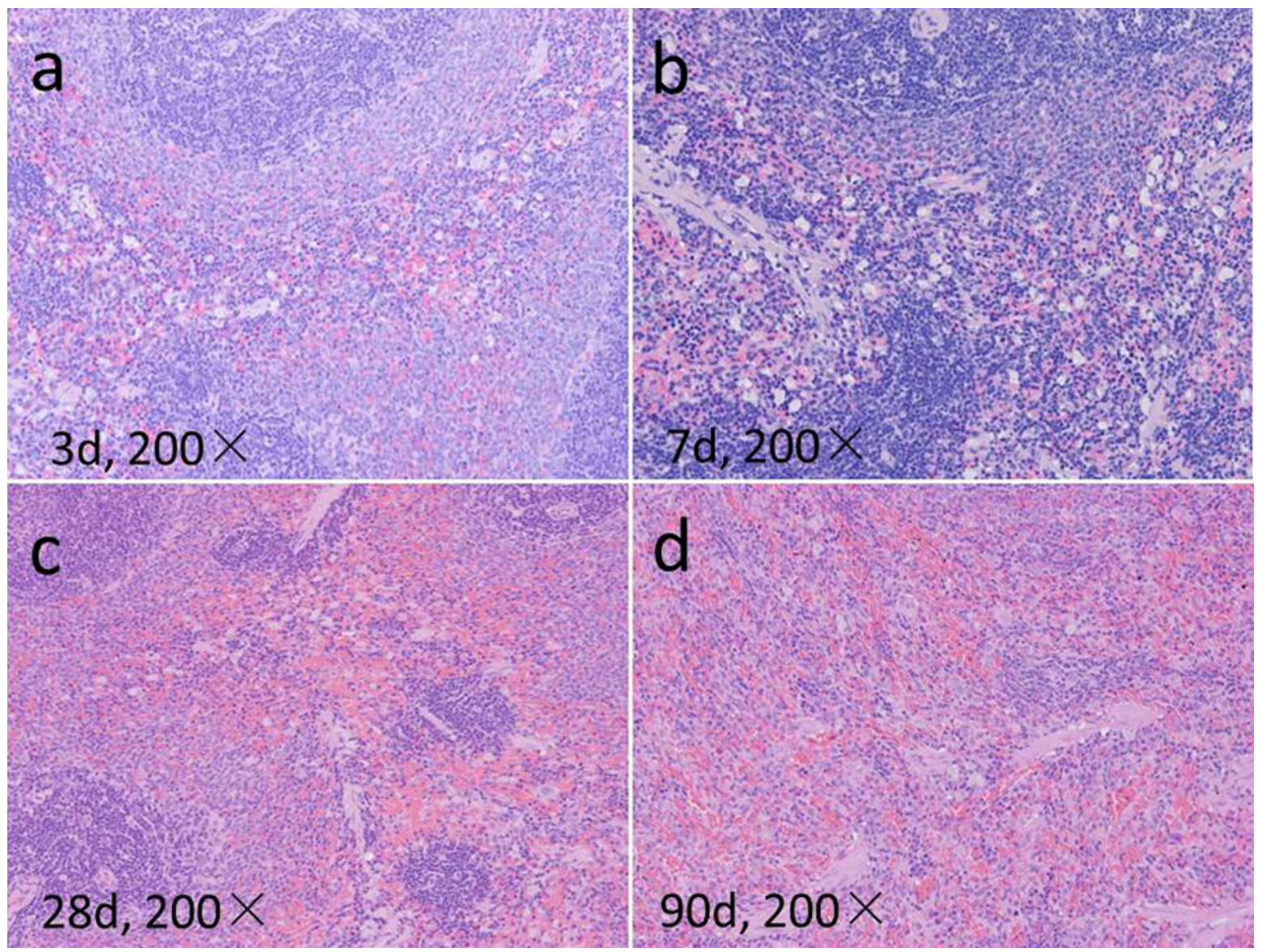

Figure 5

Time-dependence of reaction in spleen of high-dose group; mild, medium, mild and slight reactions are observed from a-d respectively

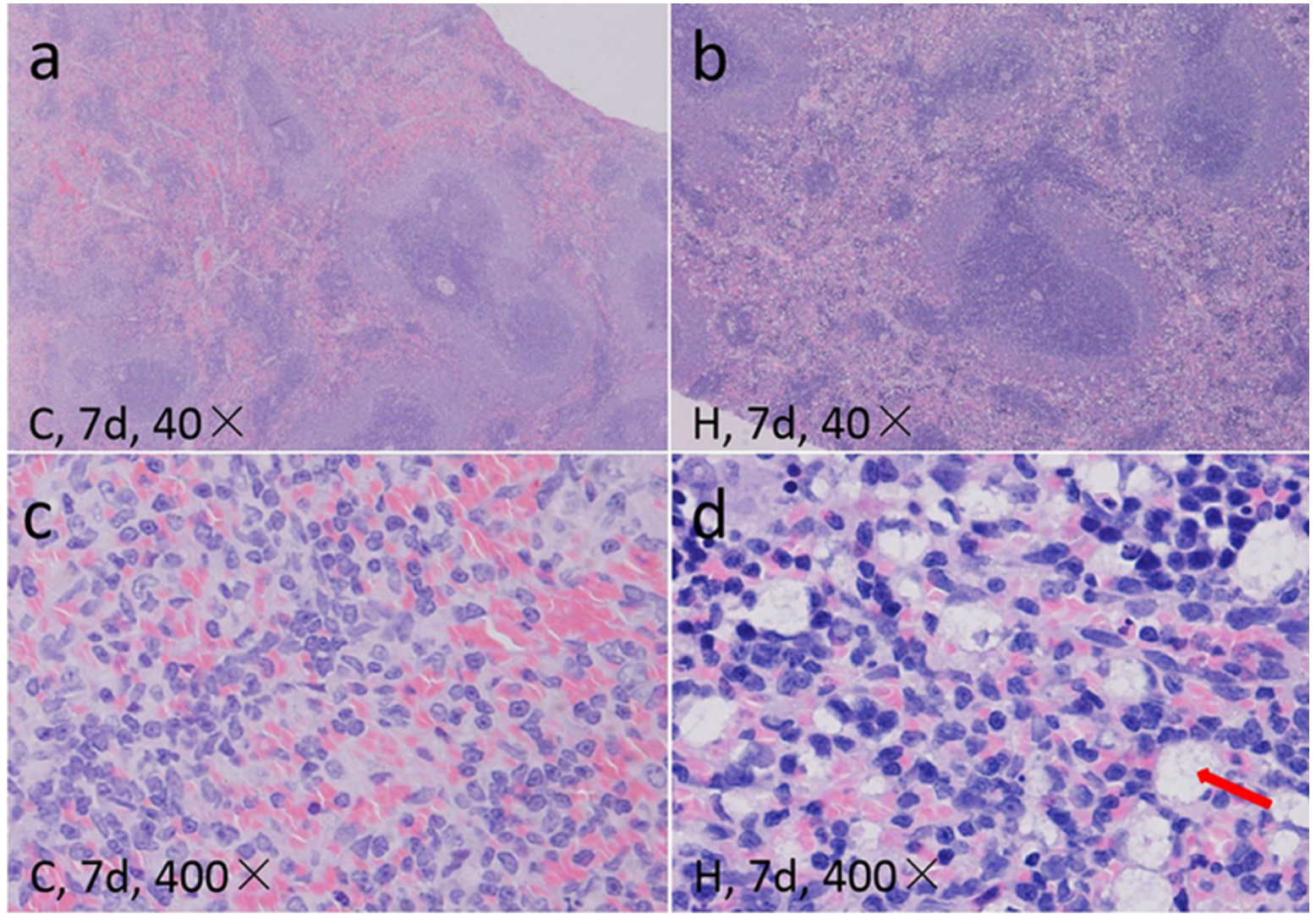

Figure 6 


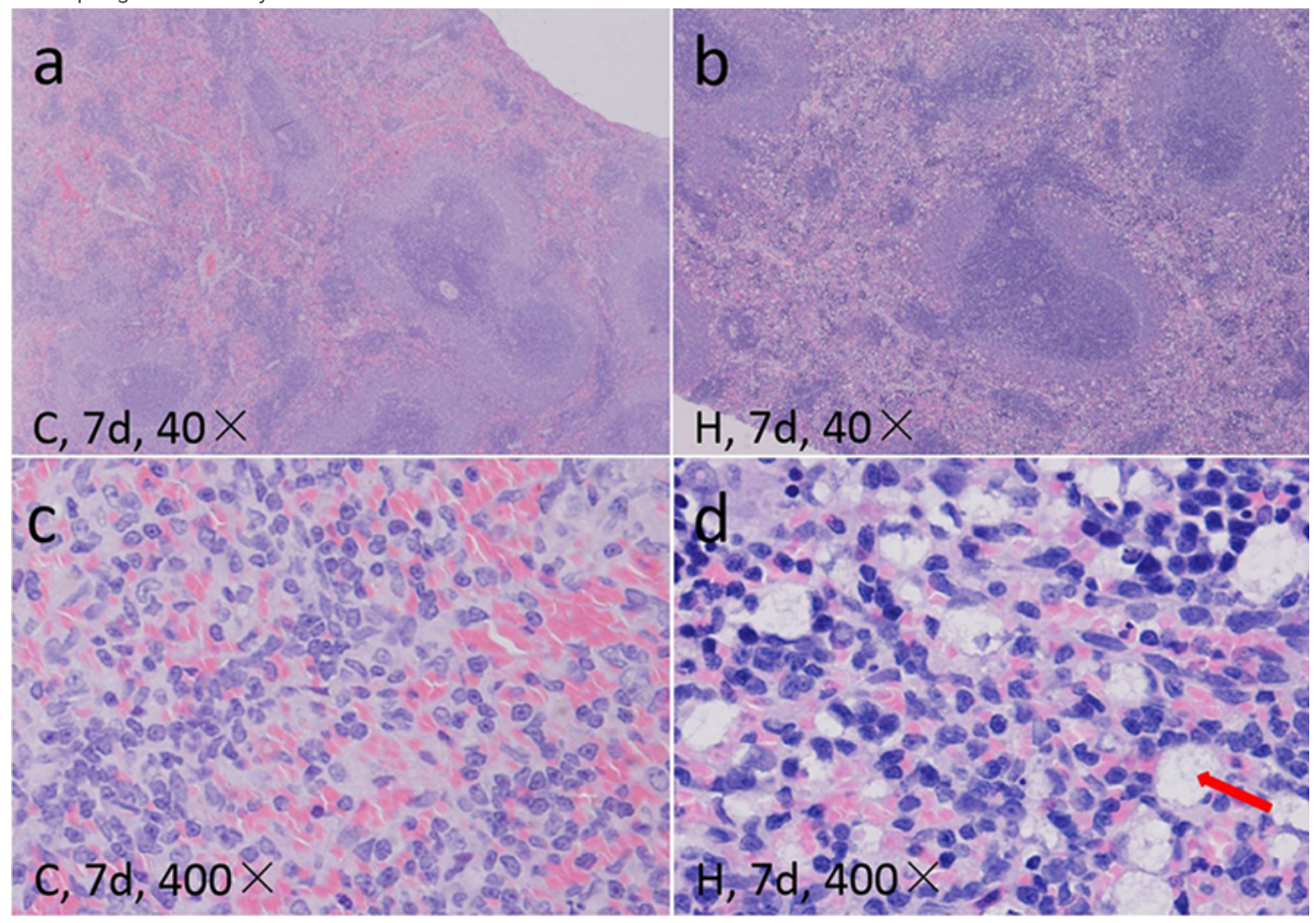

\section{Figure 6}

Histopathologic appearances of spleens in control and high-dose group 7d after injection; vacuolization can be observed from b and d; representative macrophage is shown by the red arrow in $d$

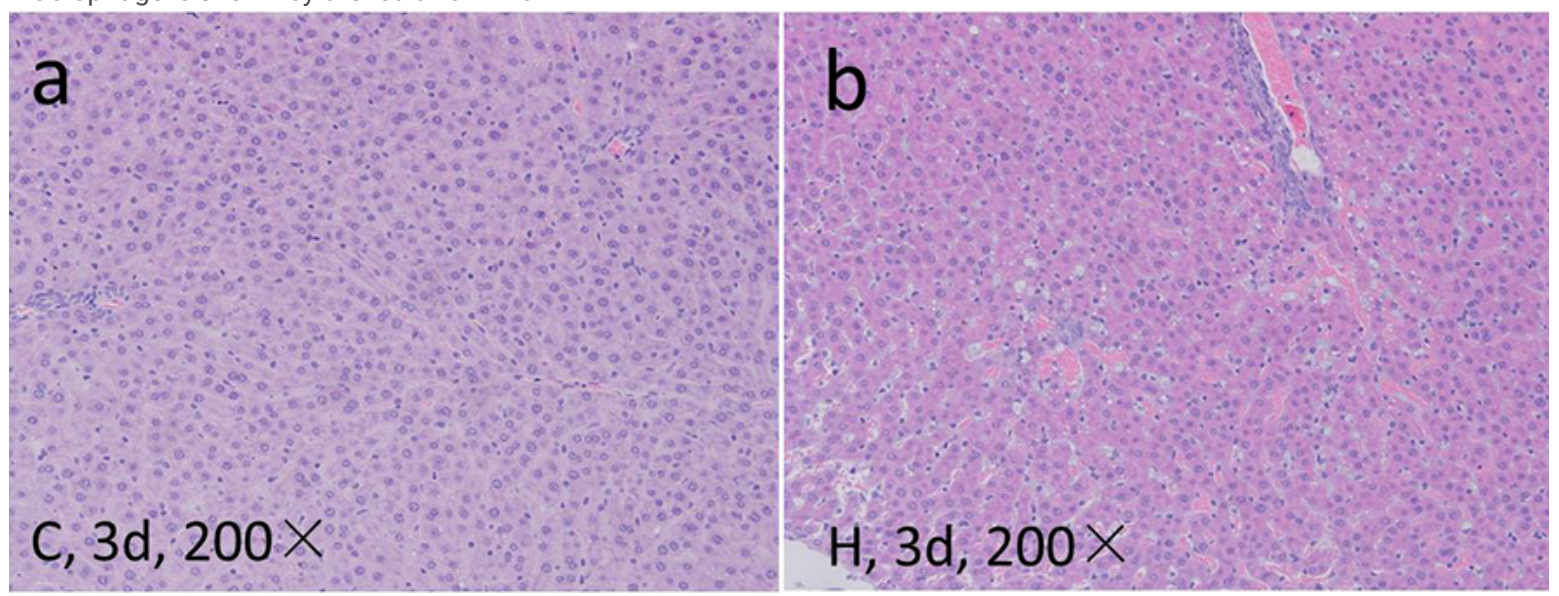

Figure 7

Histopathologic appearances of livers in control and high-dose group 3d after injection; congestion can be observed in b 


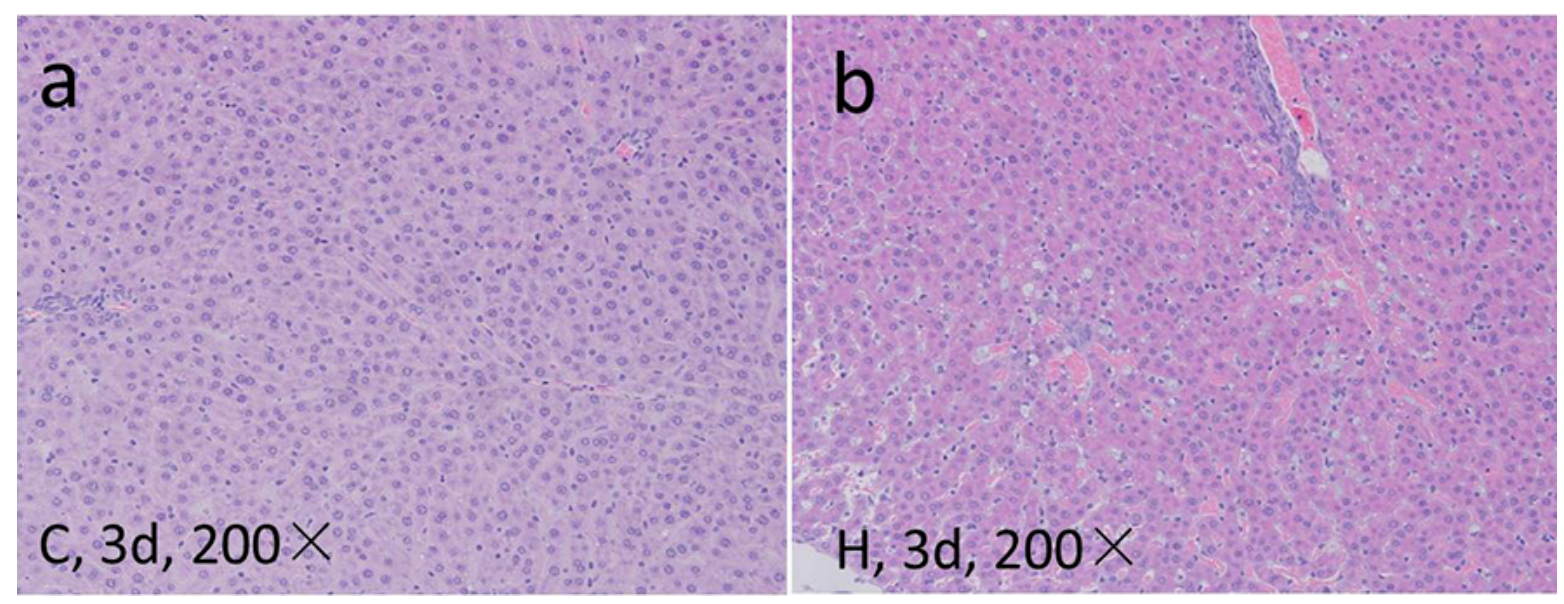

\section{Figure 7}

Histopathologic appearances of livers in control and high-dose group 3d after injection; congestion can be observed in b

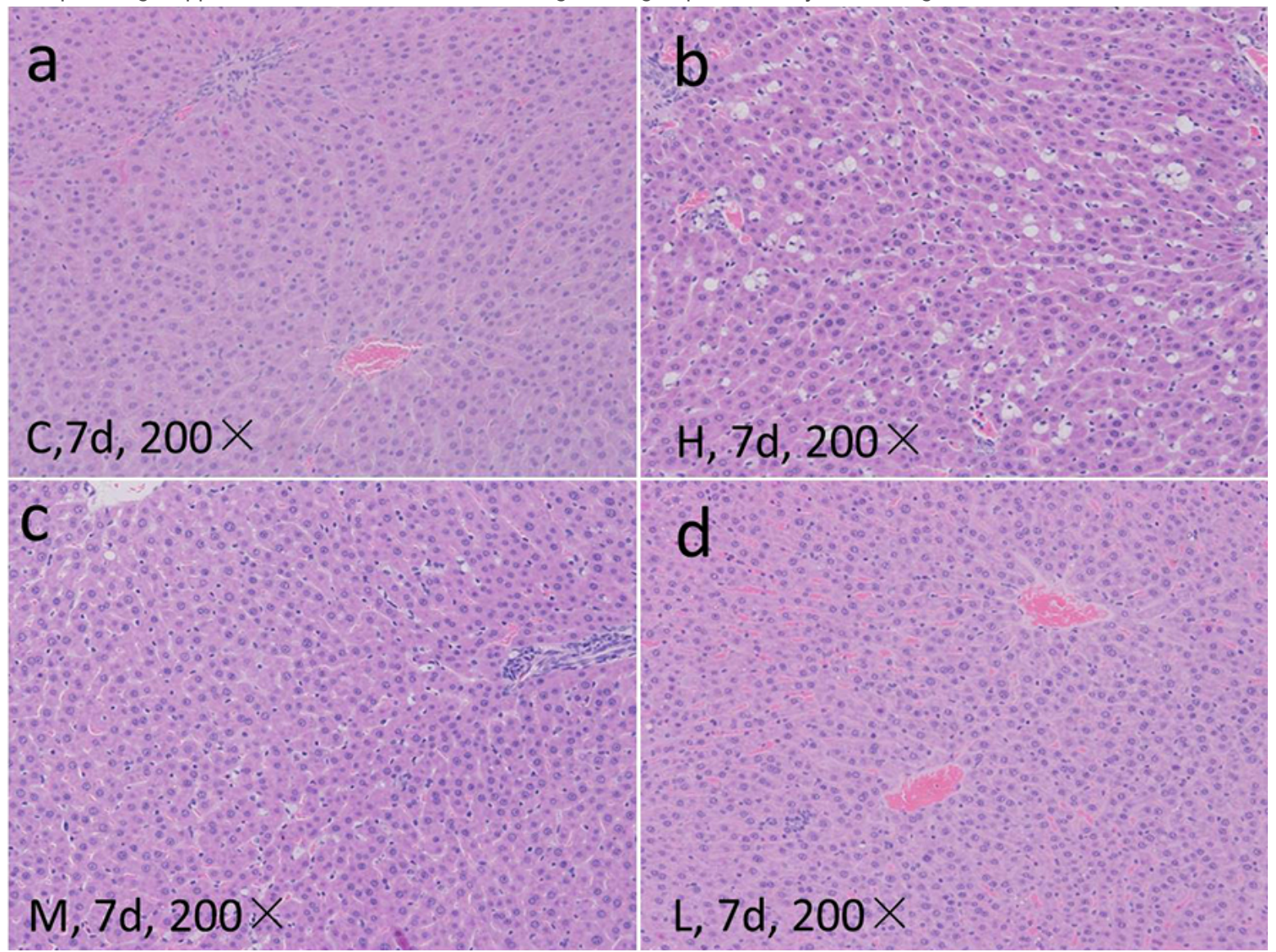

\section{Figure 8}

Dose-response of liver reactions 7d after injection; a: normal liver of control group, b: mild reactions of high-dose group, c: slight reactions of medium-dose group, d: normal liver of low-dose group 


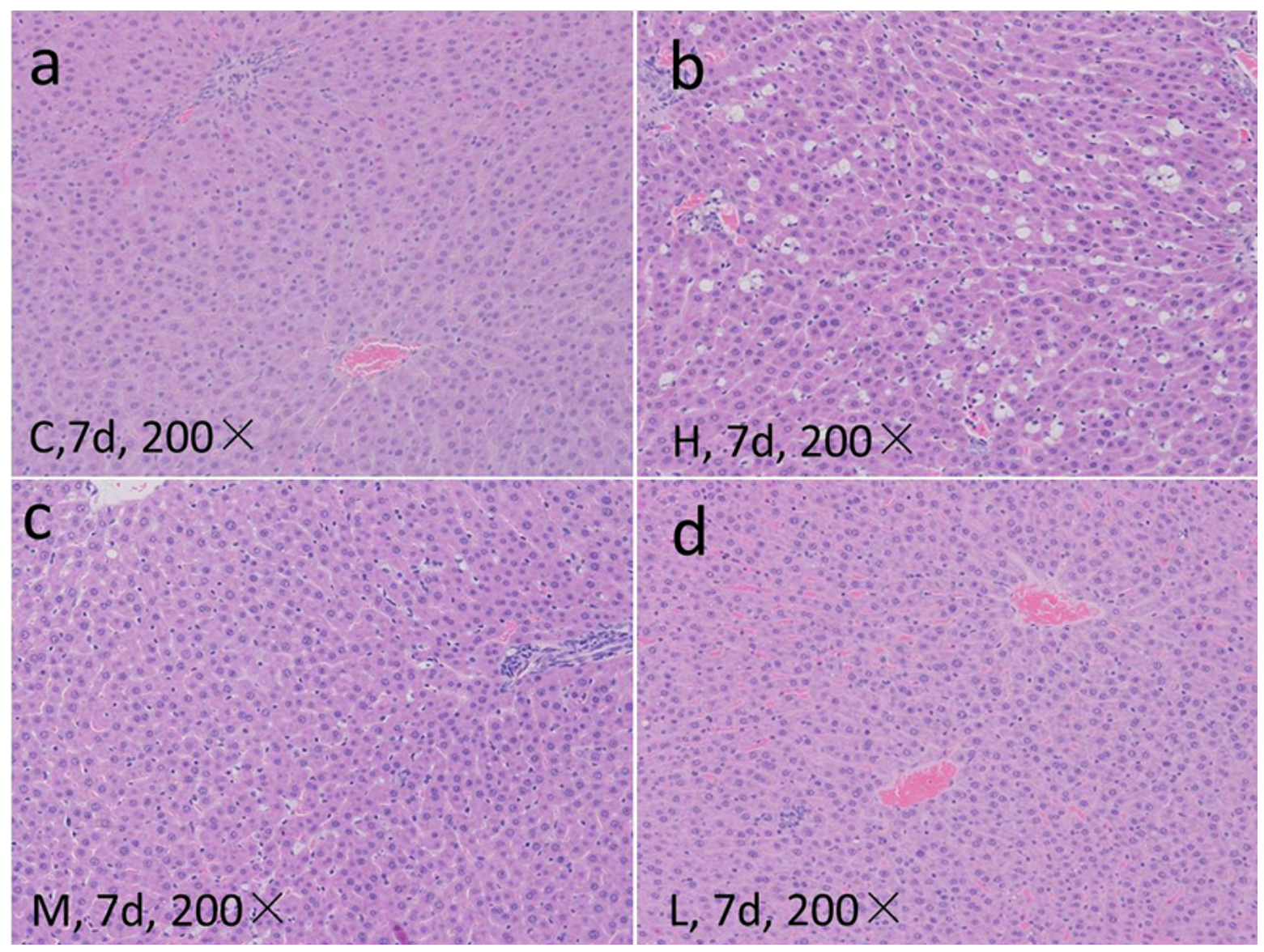

\section{Figure 8}

Dose-response of liver reactions 7d after injection; a: normal liver of control group, b: mild reactions of high-dose group, c: slight reactions of medium-dose group, d: normal liver of low-dose group 


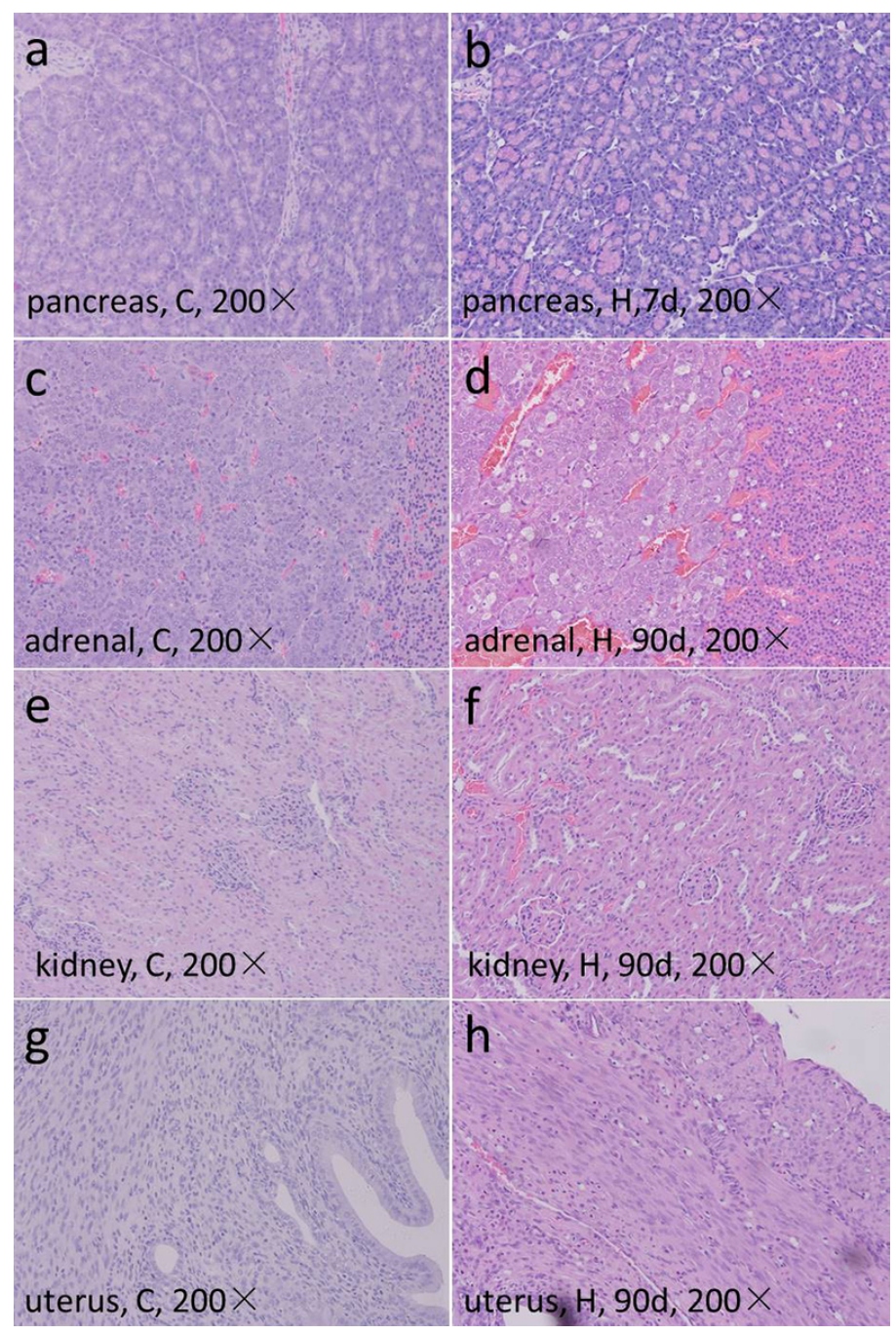

\section{Figure 9}

Reactions in multiple organs of high-dose group compared with the control 


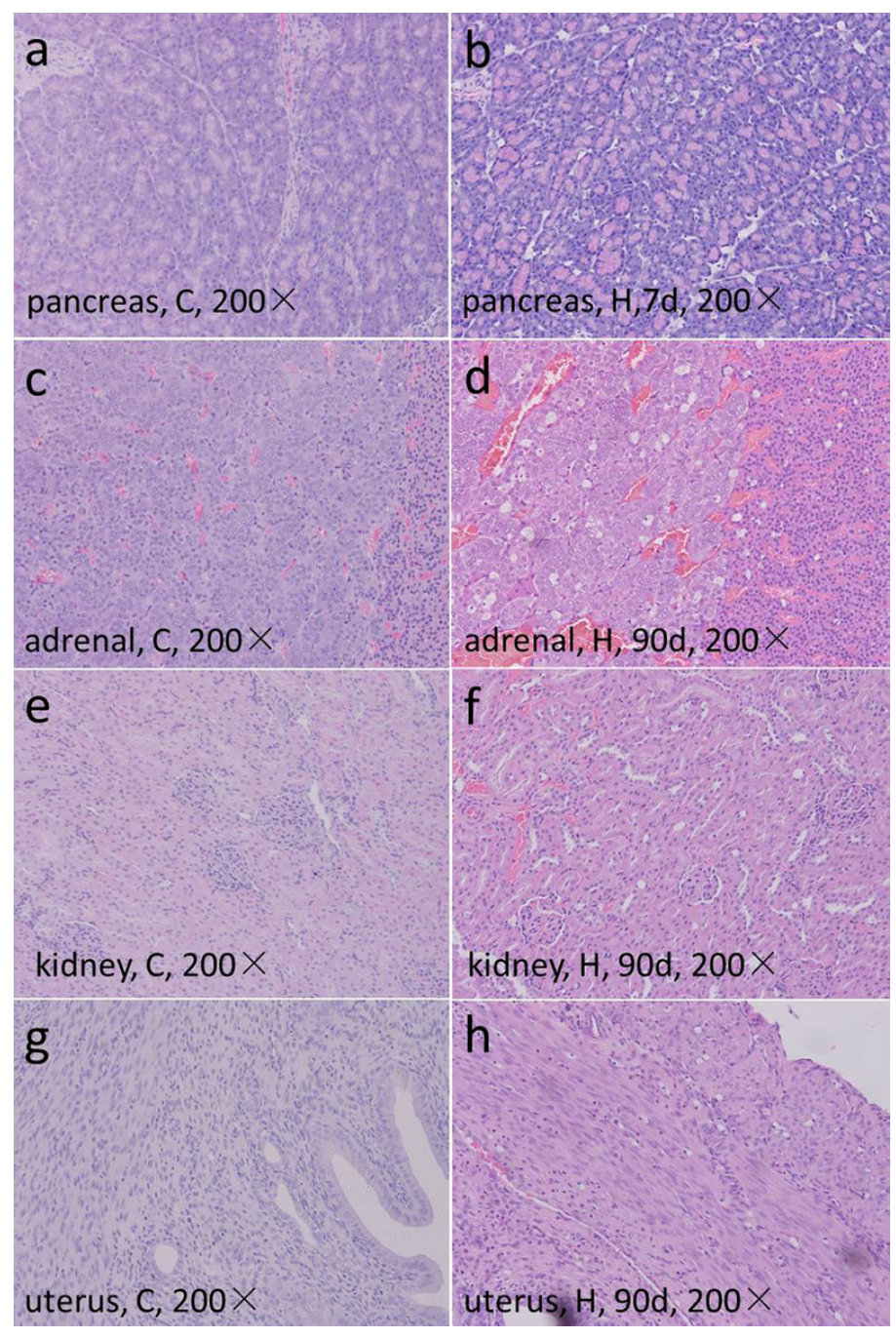

\section{Figure 9}

Reactions in multiple organs of high-dose group compared with the control 


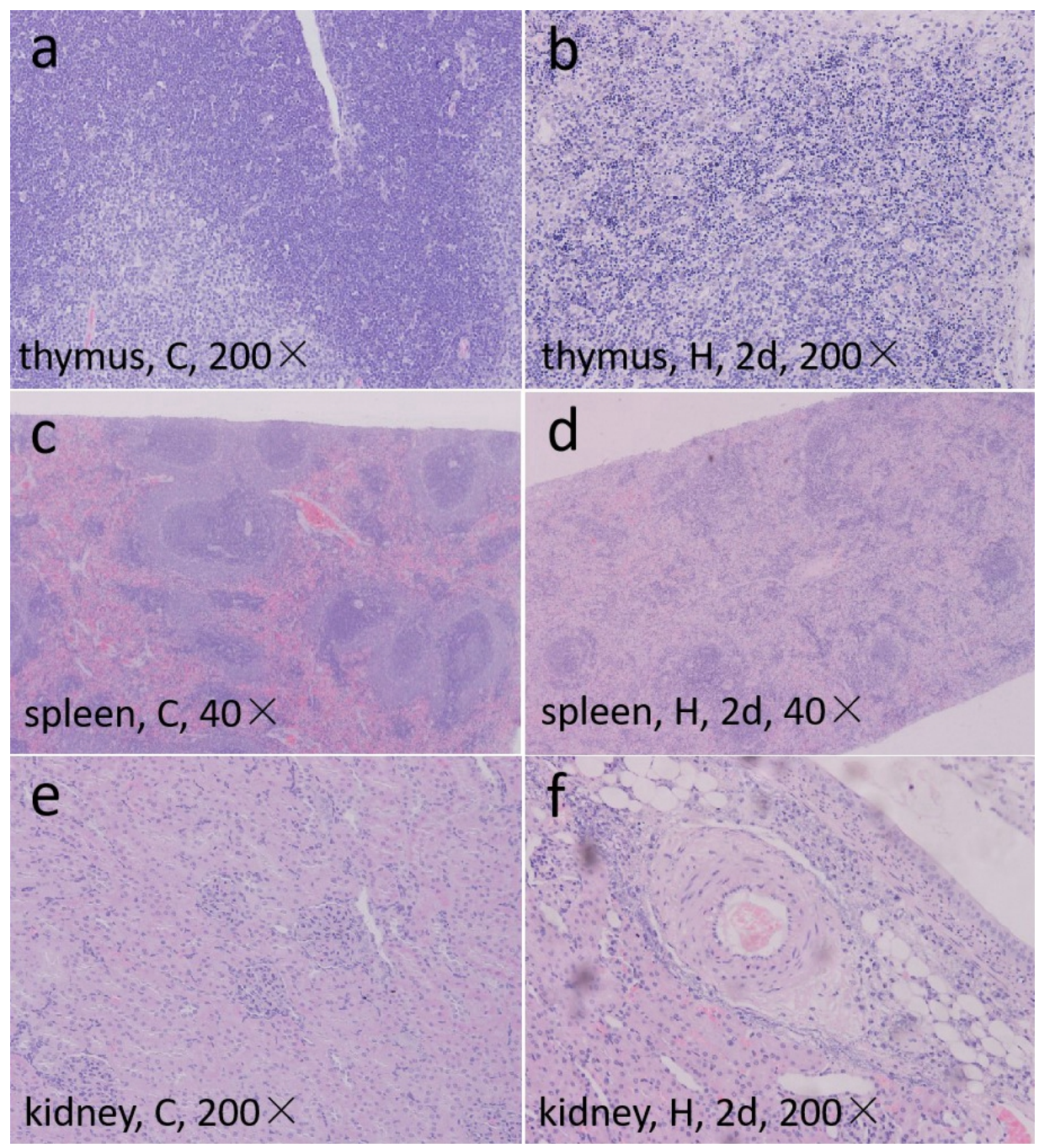

\section{Figure 10}

Histopathological appearances in some organs of dead rats compared with the control; a, c and e: normal organs of control group, b: severe lymphocytes apoptosis and decrease in cortex of thymus of dead rats, d: mild lymphocytes decrease in spleen of dead rats, f: infiltration of macrophages and polymorphic nucleus WBC in interstitium and light blue-stained substance in submucosa of kidney pelvis 


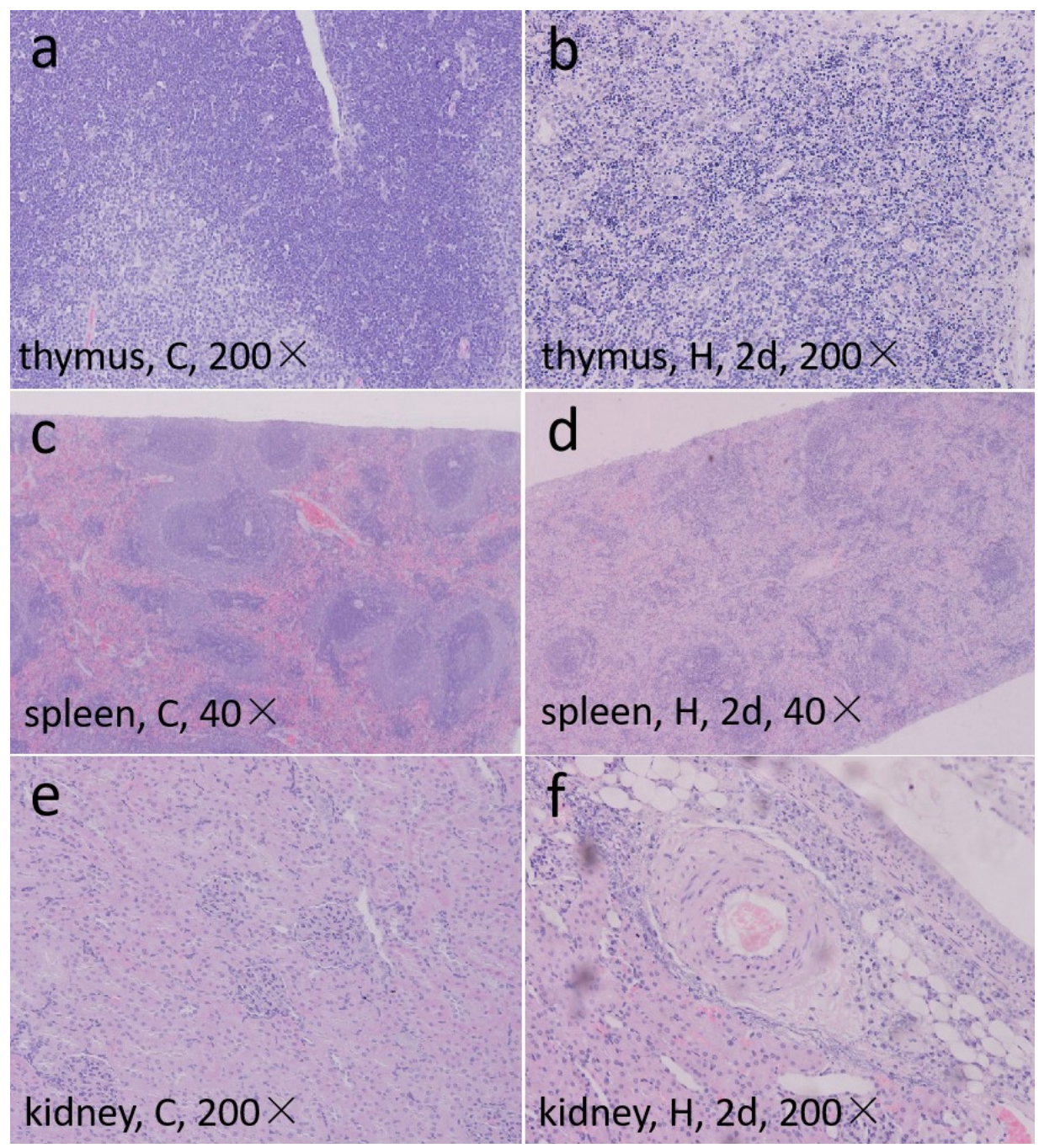

\section{Figure 10}

Histopathological appearances in some organs of dead rats compared with the control; a, c and e: normal organs of control group, b: severe lymphocytes apoptosis and decrease in cortex of thymus of dead rats, d: mild lymphocytes decrease in spleen of dead rats, f: infiltration of macrophages and polymorphic nucleus WBC in interstitium and light blue-stained substance in submucosa of kidney pelvis 